\title{
A Simple Route to Aqueous Suspensions of Degradable Copolymer Nanoparticles from Radical Ring-Opening Polymerization- Induced Self-Assembly (rROPISA)
}

Chen Zhu, Stéphanie Denis, Julien Nicolas*

Université Paris-Saclay, CNRS, Institut Galien Paris-Saclay, 92296 ChâtenayMalabry, France

*To whom correspondence should be addressed.

Email: julien.nicolas@u-psud.fr

Tel.: +33146835853 


\section{Abstract}

Degradable polymer nanoparticles are almost exclusively obtained by formulation of preformed degradable polymers, such as aliphatic polyesters, thus resulting is very low nanoparticle concentrations and limited structural diversity. On the other hand, many different vinyl polymers can be obtained by polymerization in aqueous dispersed media, but their non-degradability limits their use especially in the biomedical field. Herein, we combined the best of both worlds by developing a two-step radical ringopening copolymerization-induced self-assembly (rROPISA) process, allowing to generate aqueous suspensions of narrowly dispersed, degradable vinyl copolymer nanoparticles at $15 \mathrm{wt} . \%$ solid contents, containing cyclic ketene acetal (CKA) units in the nanoparticle core. This strategy relied on rROPISA in DMF, followed by a simple transfer step to water. It was successfully applied to the three main CKAs used in rROP and yielded nanoparticles of $\sim 80-215 \mathrm{~nm}$ in diameter with tunable amount of CKA up to $21 \mathrm{~mol} \%$. Successful incorporation of ester groups in the copolymers was demonstrated by hydrolytic degradation of both the copolymers and the nanoparticles. The nanoparticles' cytocompatibility was then established by cell viability assays and cell morphology observation with three representative healthy cell lines. Not only this synthetic strategy could be of great potential for drug delivery applications, but it can also be beneficial to other research fields to yield more environmentally friendly materials involving the use of latexes, such as paints or coatings. 


\section{Introduction}

Formulation of aqueous suspensions of degradable polymer nanoparticles has gained tremendous interest notably in the biomedical field. ${ }^{[1-4]}$ Nanoparticles based on aliphatic polyesters are still considered to be the gold standard given their biodegradability and their FDA-approval for use in humans. However, polyester nanoparticles are exclusively obtained by formulation of preformed polymers using organic solvents because of the impossibility to perform their synthesis in water-borne conditions. It therefore results in very low concentrations in nanoparticles (ca 1-5 wt.\%), which limits their use. ${ }^{[3]}$ Moreover, polyesters also exhibit strong limitations in terms of structural variation, functionalization and regarding the possibility to make sophisticated architectures.

Conversely, vinyl polymers synthesized by reversible deactivation radical polymerization (RDRP) exhibit hight structural diversity, ease of functionalization and can be obtained in aqueous dispersed media to produce polymer (nano)particles. However, their non-degradability restricts their use for most biomedical applications because their lack of metabolization and/or excretion ${ }^{[4]}$ can potentially lead to toxic accumulation of foreign materials in the body. Despite recent developments in radical ring-opening copolymerization (rROP) of cyclic ketene acetals (CKAs), ${ }^{[5-7]}$ which is the most efficient strategy to insert ester groups in the backbone of vinyl polymers, the preparation of aqueous suspensions of degradable nanoparticles by rROP is still at its infancy. ${ }^{[8]}$ Therefore, a robust yet simple polymerization process able to produce aqueous suspensions of degradable polyester-like particles is still an unmet need. Such 
materials would indeed represent an important addition to the somewhat limited arsenal of degradable polymer nanoparticles available for biomedical applications and open new perspectives regarding environmentally friendly materials.

Among the different polymerization processes in dispersed media, polymerizationinduced self-assembly (PISA) ${ }^{[9-11]}$ has established as the most versatile and robust to generate a wide range of different diblock copolymer nano-object suspensions (e.g., spheres, ${ }^{[12]}$ vesicles $^{[13-15]}$ or worms ${ }^{[16]}$ ) without surfactant and with high solids contents (ca 10-50 wt.\%). PISA has indeed shown extraordinary flexibility in terms of polymerization techniques and conditions used, ${ }^{[17-20]}$ monomers polymerized, ${ }^{[16,21-24]}$ stimuli-responsiveness $^{[23,25-28]}$ or potential applications. However, even though PISAderived nano-objects have been suggested for drug delivery or other biomedical applications, ${ }^{[12,21,29-35]}$ there is yet no strategy to achieve aqueous suspension of degradable, polyester-like nanoparticles by PISA. Conversely, PISA was recently successfully applied to the synthesis of synthetic polypeptide nanoparticles by NCA polymerization. ${ }^{[36]}$

Herein, we tackled these challenges by developing a simple, yet robust two-step approach to generate aqueous suspensions of degradable polyester-like nanoparticles by PISA. To do so, we built on our recently developed rROPISA process, ${ }^{[37,38]}$ a combination between PISA and rROP that served to produce nanoparticles in non-polar solvents. In the present work, the rROPISA process was redesigned to make it fully compatible with the preparation of aqueous suspensions of degradable diblock copolymer nanoparticles (Figure 1). To demonstrate the flexibility of this process, it 
was successfully applied to the three main CKAs used in rROP; namely 2-methylene4-phenyl-1,3-dioxolane (MPDL), 5,6-benzo-2-methylene-1,3-dioxepane (BMDO) and 2-methylene-1,3-dioxepane (MDO). Also, by a careful selection of the different polymer blocks, not only the nanoparticles exhibited a biocompatible shell, ${ }^{[39-43]}$ but they also showed excellent cytocompatibility on representative healthy human cells.

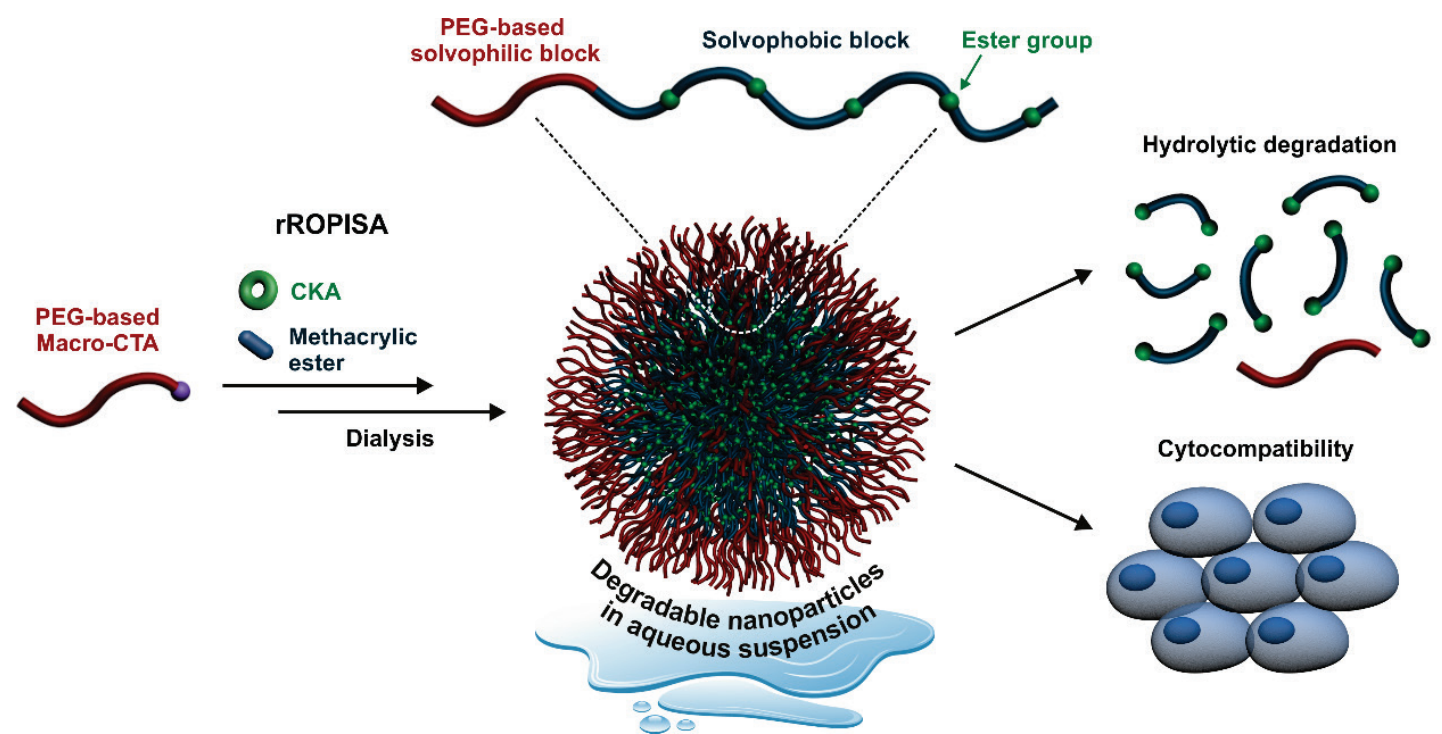

Figure 1. Synthesis of aqueous suspensions of core-degradable diblock copolymer nanoparticles by consecutive radical ring-opening copolymerization-induced self-assembly (rROPISA) from cyclic ketene acetals (CKAs), followed by transfer to water. 


\section{Materials and Methods}

\subsection{Materials}

Lauryl methacrylate (LMA, 96\%) and oligo(ethylene glycol) methyl ether methacrylate (OEGMA, $M_{\mathrm{n}}=300$ g.mol ${ }^{-1}$ ) were purchased from Sigma-Aldrich and passed through basic alumina before use. 4-Cyano-4[(dodecylsulfanylthiocarbonyl)sulfanyl]pentanoic acid (CDSPA, 97\%), anhydrous $N$ $N^{\prime}$-dimethylformamide (DMF) and 2,2'-azobis(2-methylpropionitrile) (AIBN, 98\%) were purchased from Sigma-Aldrich and used as received. Tert-butyl peroxy-2ethylhexanoate (Trigonox 21S or T21s) initiator was supplied by AkzoNobel. Deuterated chloroform $\left(\mathrm{CDCl}_{3}\right)$ and tetrahydrofuran (TDF) were obtained from Eurisotop. 2-Methylene-4-phenyl-1,3-dioxolane (MPDL), 2-methylene-1,3-dioxepane (MDO) and 5,6-benzo-2-methylene-1,3-dioxepane (BMDO) were prepared from the cyclic bromoacetal intermediate as described elsewhere. ${ }^{[4]}$ All other solvents were purchased from Carlo-Erba and used as received. [3-(4,5-Dimethylthiazol-2-yl)-2,5diphenyl tetrazolium bromide] (MTT) was purchased from Sigma-Aldrich and used as received.

\subsection{Analytical method}

2.2.1. Nuclear magnetic resonance (NMR) spectroscopy. ${ }^{1} \mathrm{H}-\mathrm{NMR}$ spectroscopy was performed in $5 \mathrm{~mm}$ diameter tubes in deuterated chloroform $\left(\mathrm{CDCl}_{3}\right)$ or tetrahydrofuran (TDF) at $25^{\circ} \mathrm{C}$ on a Bruker Avance 300 spectrometer at $300 \mathrm{MHz}$. The chemical shift 
scale was calibrated based on the internal solvent signal $\left(\mathrm{CDCl}_{3}: \delta=7.26 \mathrm{ppm}\right.$; TDF: $\delta=1.72$ and $3.58 \mathrm{ppm})$.

2.2.2. Size exclusion chromatography (SEC). SEC was performed at $35^{\circ} \mathrm{C}$ with two columns from Polymer Laboratories (PL-gel MIXED-D; $300 \times 7.5 \mathrm{~mm}$; bead diameter, $5 \mu \mathrm{m}$; linear part, 400-400 000 g. $\mathrm{mol}^{-1}$ ) and a differential refractive index detector (Spectrasystem RI-150 from Thermo Electron Corp.). Chloroform was used as eluent at a flow rate of $1 \mathrm{~mL} \cdot \mathrm{min}^{-1}$ and toluene as a flow-rate marker. A conventional calibration curve was based on poly(methyl methacrylate) (PMMA) standards (peak molar masses, $M_{\mathrm{p}}=625-625500 \mathrm{~g} \cdot \mathrm{mol}^{-1}$ ) from Polymer Laboratories. This technique allowed $M_{\mathrm{n}}$ (number-average molar mass), $M_{\mathrm{w}}$ (weight-average molar mass), and $M_{\mathrm{w}} / M_{\mathrm{n}}$ (dispersity, $\left.Ð\right)$ to be determined. SEC of degraded copolymers was performed in the presence of $0.1 \mathrm{vol} \%$ of trifluoroacetic acid (TFA, 99\%) in chloroform (in both the mobile phase and the sample) to avoid the formation of aggregates and/or interaction with the columns because of carboxylic acid chain ends.

2.2.3. Dynamic light scattering (DLS). Nanoparticle diameters, reported in number $\left(D_{\mathrm{n}}\right)$, volume $\left(D_{\mathrm{v}}\right)$ and intensity $\left(D_{\mathrm{z}}\right)$, and particle size distribution (PSD) were measured by dynamic light scattering (DLS) with a Nano ZS from Malvern $\left(173^{\circ}\right.$ scattering angle) at a temperature of $25^{\circ} \mathrm{C}$.

2.2.4. Transmission electron microscopy (TEM). Grids were glowing discharged before use. $5 \mu \mathrm{L}$ of diluted nanoparticle suspensions (5\%, v/v) were deposited for $30 \mathrm{~s}$ on copper grids covered with formvar-carbon film. The excess solution was blotted off using a filter paper. Samples were then stained using uranyl acetate $(2 \%, w / v)$ for $1-5$ 
min at room temperature. Then the excess solution was removed using a filter paper. The grids were then analyzed using a JEOL JEM-1400 operating at $80 \mathrm{kV}$. Images were acquired using an Orius camera (Gatan Inc, USA). The nanoparticles were analyzed by defining the number-average diameter $\left(D_{\mathrm{n}}\right)$, the weight-average diameter $\left(D_{\mathrm{w}}\right)$, the zaverage diameter $\left(D_{\mathrm{z}}\right)$ and the polydispersity index (PDI) using the following equations: $D_{\mathrm{n}}=\frac{\sum_{i} n_{i} \cdot D_{i}}{\sum_{i} n_{i}}$

$D_{\mathrm{w}}=\frac{\sum_{i} n_{i} \cdot D_{i}^{4}}{\sum_{i} n_{i} \cdot D_{i}^{3}}$

$D_{\mathrm{z}}=\frac{\sum_{i} n_{i} \cdot D_{i}{ }^{6}}{\sum_{i} n_{i} \cdot D_{i}{ }^{5}}$

$\mathrm{PDI}=D_{\mathrm{w}} / D_{\mathrm{n}}$

2.2.5. Cryogenic transmission electron microscopy (Cryo-TEM). Grids were prepared using a Vitrobot Mark IV (Thermo Fisher), operating at $20^{\circ} \mathrm{C}$ and under $100 \%$ humidity. $4 \mu \mathrm{L}$ of undiluted nanoparticle suspensions were deposited on freshly glow discharged Quantifoil R2/2, 200 mesh grids. The grids were blotted for $5 \mathrm{~s}$ with blot force 0 , and then plunge-frozen into liquid ethane cooled down at liquid nitrogen temperature. The grids were then analyzed using a Tecnai G20 (FEG, FEI) microscope operating at $200 \mathrm{kV}$, equipped with a K2 Summit direct-detection camera. Images were recorded at $15.000 \times$ magnification, with a pixel size of $2.5 \AA$ at $20 \mathrm{e}^{-} / \AA^{2}$.

2.2.6. Optical microscopy. Optical images of cells were captured with an AxioObserver Z1 (Carl Zeiss, Germany) inverted microscope equipped with a XL incubator thermostated at $37^{\circ} \mathrm{C}$, a charge-coupled device (CCD) CoolSnap-HQ2 camera $(6.45 \mu \mathrm{m}$ pixel size; Photometrics, Tucson, USA) and an Achroplan 4X/0.10 
NA dry objective lens using a brightfield mode (TL halogen lamp). Images (12 bits numerical) were processed using Zen 2.6 software (blue edition).

\subsection{Synthetic procedures}

\subsubsection{Synthesis of poly[oligo(ethylene glycol) methyl ether methacrylate]} (POEGMA) macro-chain transfer agent (CTA). The synthesis of POEGMA 23 was conducted as follows: in a $50 \mathrm{~mL}$ round bottom flask, fitted with a rubber septum and a magnetic stirring bar, a mixture of OEGMA (3.680 g, $0.012 \mathrm{~mol})$, AIBN (9.6 mg, $\left.5.93 \times 10^{-2} \mathrm{mmol}\right)$, CDSPA $\left(0.097 \mathrm{~g}, 2.41 \times 10^{-1} \mathrm{mmol}\right.$, CDSPA/AIBN molar ratio $=$ 4.0) and acetonitrile $(25 \mathrm{~mL})$ was degassed by argon bubbling for at least $15 \mathrm{~min}$ at room temperature. The mixture was then immersed in a preheated oil bath at $70{ }^{\circ} \mathrm{C}$ for $5 \mathrm{~h}$. Monomer conversion was determined by ${ }^{1} \mathrm{H}$ NMR spectroscopy by integrating the two oxymethylene protons of OEGMA and POEGMA at 4.3 and $4.1 \mathrm{ppm}$, respectively. After the reaction, the polymer solution was cooled in an ice water bath. Acetonitrile was then removed under reduced pressure and the polymer was precipitated in a large excess of cold 1:1 diethyl ether/petroleum spirit mixture. The purified polymer was dried under high vacuum until constant weight. $D P_{\mathrm{n}, \mathrm{NMR}}$ was determined by ${ }^{1} \mathrm{H}$ NMR spectroscopy by integrating the two oxymethylene protons of POEGMA at $4.1 \mathrm{ppm}$ and the eighteen protons of the $\mathrm{C}_{12}$ alkyl chains of CDSPA at 1.2-1.4 ppm. $D P_{\mathrm{n}, \mathrm{SEC}}, M_{\mathrm{n}}$ and $Ð$ were obtained by SEC.

The same procedure was followed with the following modifications to obtain the POEGMA $_{52}$ macro-CTA: OEGMA (5.40 g, $\left.0.018 \mathrm{~mol}\right)$, AIBN (4.5 mg, $2.78 \times 10^{-2}$ $\mathrm{mmol}), \operatorname{CDSPA}\left(0.050 \mathrm{~g}, 1.24 \times 10^{-1} \mathrm{mmol}\right)$ and acetonitrile $(12.5 \mathrm{~mL})$. 
2.3.2. Block copolymer synthesis. For the sake of clarity, the following abbreviations will now be used: OEGMA $=$ OEG, LMA $=\mathrm{L}, \mathrm{m}=D P_{\mathrm{n}, \text { POEGMA }}, \mathrm{n}=D P_{\mathrm{n}, \mathrm{PLMA}}$, POEGMA- $b-\mathrm{PLMA}=\mathbf{O E G}_{\mathbf{m}}-\mathbf{L}_{\mathbf{n}}(\mathbf{M P 0}$ and MP5), POEGMA- $b-\mathrm{P}(\mathrm{LMA}-c o-\mathrm{MPDL})=$ OEGm-LnMP (MP1-MP9), POEGMA- $b$-P(LMA-co-BMDO) = OEGm-LnB (BM1BM4 $)$ and POEGMA- $b-\mathrm{P}($ LMA-co-MDO $)=\mathbf{O E G}_{\mathbf{m}}-\mathbf{L}_{\mathbf{n}} \mathbf{M}(\mathbf{M 1 - M 4})$.

Synthesis of poly[oligo(ethylene glycol) methyl ether methacrylate]-b-poly[(lauryl methacrylate)-co-(2-methylene-4-phenyl-1,3-dioxolane)] (POEGMA-b-P(LMA-co$M P D L)$ ). A typical synthesis of POEGMA $23-b-\mathrm{P}\left(\mathrm{LMA}_{150}-c o-\mathrm{MPDL}\right)$ (OEG23L150MP) by RAFT dispersion polymerization at $15 \mathrm{wt} . \%$ solids with $f_{\mathrm{MPDL}, 0}=0$ (MP0) was as follows: in a $40 \mathrm{~mL}$ vial, fitted with a rubber septum and a magnetic stirring bar, a mixture of LMA $\left(0.512 \mathrm{~g}, 2.02 \times 10^{-3} \mathrm{~mol}\right), \mathrm{T} 21 \mathrm{~s}$ initiator $\left(0.6 \mathrm{mg}, 2.78 \times 10^{-3} \mathrm{mmol}\right.$, dissolved at $0.1 \% \mathrm{w} / \mathrm{v}$ in DMF) and POEGMA 23 macro-CTA $\left(0.098 \mathrm{~g}, 1.32 \times 10^{-2}\right.$ mmol; macro-CTA/initiator molar ratio $=5.0)$ in anhydrous DMF $(3.41 \mathrm{~g}, 3.6 \mathrm{~mL})$ was degassed by argon bubbling for at least $15 \mathrm{~min}$ and then immersed in a preheated oil bath at $90{ }^{\circ} \mathrm{C}$ for $24 \mathrm{~h}$. Samples were periodically withdrawn to determine the LMA conversion by ${ }^{1} \mathrm{H}$ NMR spectroscopy by integrating the two oxymethylene protons of LMA at 5.5 and $6.0 \mathrm{ppm}$ with PLMA protons at $3.8 \mathrm{ppm} . M_{\mathrm{n}}$ and $Ð$ were determined by SEC. The nanoparticle colloidal characteristics, $D_{z}$ and PSD, were obtained by DLS. The nanoparticles were dried under reduced pressure at $40{ }^{\circ} \mathrm{C}$ and solubilized in a minimal amount of dichloromethane (DCM) before precipitation in cold methanol. The purified copolymer was collected after centrifugation $(10000 \mathrm{rpm}, 30 \mathrm{~min})$ and dried under high vacuum until constant weight. 
The same procedure was performed with: $f_{\text {MPDL }, 0}=0.2$ (MP1) [LMA (0.504 g, 1.99 $\left.\times 10^{-3} \mathrm{~mol}\right), \operatorname{MPDL}\left(0.081 \mathrm{~g}, 5.00 \times 10^{-1} \mathrm{mmol}\right), \mathrm{T} 21 \mathrm{~s}$ initiator $\left(0.6 \mathrm{mg}, 2.78 \times 10^{-3}\right.$ mmol, dissolved at $0.1 \% \mathrm{w} / \mathrm{v}$ in DMF), POEGMA 23 macro-CTA $\left(0.102 \mathrm{~g}, 1.38 \times 10^{-2}\right.$ mmol, DMF (3.9 g, $4.1 \mathrm{~mL})] ; f_{\mathrm{MPDL}, 0}=0.4(\mathbf{M P 2})\left[\mathrm{LMA}\left(0.511 \mathrm{~g}, 2.01 \times 10^{-3} \mathrm{~mol}\right)\right.$, MPDL $\left(0.214 \mathrm{~g}, 1.32 \times 10^{-3} \mathrm{~mol}\right), \mathrm{T} 21 \mathrm{~s}$ initiator $\left(0.6 \mathrm{mg}, 2.78 \times 10^{-3} \mathrm{mmol}\right.$, dissolved at $0.1 \% \mathrm{w} / \mathrm{v}$ in DMF), POEGMA 23 macro-CTA $\left(0.103 \mathrm{~g}, 1.39 \times 10^{-2} \mathrm{mmol}\right)$ and DMF $(4.7 \mathrm{~g}, 5.0 \mathrm{~mL})] ; f_{\mathrm{MPDL}, 0}=0.6(\mathbf{M P 3})\left[\operatorname{LMA}\left(0.507 \mathrm{~g}, 2.00 \times 10^{-3} \mathrm{~mol}\right), \operatorname{MPDL}(0.476\right.$ $\left.\mathrm{g}, 2.94 \times 10^{-3} \mathrm{~mol}\right), \mathrm{T} 21 \mathrm{~s}$ initiator $\left(0.6 \mathrm{mg}, 2.78 \times 10^{-3} \mathrm{mmol}\right.$, dissolved at $0.1 \% \mathrm{~W} / \mathrm{v}$ in DMF), POEGMA 23 macro-CTA $\left(0.095 \mathrm{~g}, 1.28 \times 10^{-2} \mathrm{mmol}\right)$ and DMF $\left.(6.2 \mathrm{~g}, 6.5 \mathrm{~mL})\right]$ and $f_{\text {MPDL }, 0}=0.7\left(\right.$ MP4) [LMA $\left(0.500 \mathrm{~g}, 1.97 \times 10^{-3} \mathrm{~mol}\right), \operatorname{MPDL}\left(0.785 \mathrm{~g}, 4.85 \times 10^{-}\right.$ $\left.{ }^{3} \mathrm{~mol}\right)$, T21s initiator $\left(0.6 \mathrm{mg}, 2.78 \times 10^{-3} \mathrm{mmol}\right.$, dissolved at $0.1 \% \mathrm{w} / \mathrm{v}$ in DMF $)$ and POEGMA $_{23}$ macro-CTA $\left(0.099 \mathrm{~g}, 1.34 \times 10^{-2} \mathrm{mmol}\right)$ and DMF $\left.(7.6 \mathrm{~g}, 8.0 \mathrm{~mL})\right]$.

The same procedure was performed with POEGMA52 macro-CTA, a targeted $D P_{\mathrm{n}, \mathrm{PLMA}}=300\left(\right.$ OEG52-L300MP) $_{\text {3 }}$ and with: $f_{\mathrm{MPDL}, 0}=0$ (MP5) [LMA $(0.503 \mathrm{~g}, 1.98 \times$ $\left.10^{-3} \mathrm{~mol}\right), \mathrm{T} 21 \mathrm{~s}$ initiator $\left(0.2 \mathrm{mg}, 9.26 \times 10^{-4} \mathrm{mmol}\right.$, dissolved at $0.1 \% \mathrm{w} / \mathrm{v}$ in DMF $)$ and POEGMA52 macro-CTA $\left(0.107 \mathrm{~g}, 6.65 \times 10^{-3} \mathrm{mmol}\right)$ and DMF $\left.(3.5 \mathrm{~g}, 3.7 \mathrm{~mL})\right]$; $f_{\text {MPDL }, 0}=0.2\left(\right.$ MP6) [LMA $\left(0.500 \mathrm{~g}, 1.97 \times 10^{-3} \mathrm{~mol}\right)$, MPDL $\left(0.082 \mathrm{~g}, 5.06 \times 10^{-1}\right.$ mmol), T21s initiator $\left(0.3 \mathrm{mg}, 1.39 \times 10^{-3} \mathrm{mmol}\right.$, dissolved at $0.1 \% \mathrm{w} / \mathrm{v}$ in DMF) and POEGMA52 macro-CTA $\left(0.105 \mathrm{~g}, 6.52 \times 10^{-3} \mathrm{mmol}\right)$ and DMF $\left.(3.9 \mathrm{~g}, 4.1 \mathrm{~mL})\right] ; f_{\mathrm{MPDL}, 0}$ $=0.4($ MP7 $)\left[\operatorname{LMA}\left(0.503 \mathrm{~g}, 1.98 \times 10^{-3} \mathrm{~mol}\right), \operatorname{MPDL}\left(0.215 \mathrm{~g}, 1.33 \times 10^{-3} \mathrm{~mol}\right), \mathrm{T} 21 \mathrm{~s}\right.$ initiator $\left(0.2 \mathrm{mg}, 9.26 \times 10^{-4} \mathrm{mmol}\right.$, dissolved at $0.1 \% \mathrm{w} / \mathrm{v}$ in DMF) and POEGMA 52 $\operatorname{macro-CTA}\left(0.107 \mathrm{~g}, 6.65 \times 10^{-3} \mathrm{mmol}\right)$ and $\left.\mathrm{DMF}(4.6 \mathrm{~g}, 4.9 \mathrm{~mL})\right] ; f_{\mathrm{MPDL}, 0}=0.6(\mathbf{M P 8})$ 
[LMA $\left(0.510 \mathrm{~g}, 2.01 \times 10^{-3} \mathrm{~mol}\right)$, MPDL $\left(0.476 \mathrm{~g}, 2.94 \times 10^{-3} \mathrm{~mol}\right)$, T21s initiator $(0.2$ $\mathrm{mg}, 9.26 \times 10^{-4} \mathrm{mmol}$, dissolved at $0.1 \% \mathrm{w} / \mathrm{v}$ in DMF) and POEGMA 52 macro-CTA $\left(0.107 \mathrm{~g}, 6.65 \times 10^{-3} \mathrm{mmol}\right)$ and $\left.\operatorname{DMF}(6.1 \mathrm{~g}, 6.4 \mathrm{~mL})\right]$ and $f_{\mathrm{MPDL}, 0}=0.7$ (MP9) [LMA $\left(0.501 \mathrm{~g}, 1.97 \times 10^{-3} \mathrm{~mol}\right)$, MPDL $\left(0.758 \mathrm{~g}, 4.68 \times 10^{-3} \mathrm{~mol}\right), \mathrm{T} 21 \mathrm{~s}$ initiator $(0.2 \mathrm{mg}$, $9.26 \times 10^{-4} \mathrm{mmol}$, dissolved at $0.1 \% \mathrm{w} / \mathrm{v}$ in DMF $)$ and POEGMA 52 macro-CTA $(0.107$ $\left.\mathrm{g}, 6.65 \times 10^{-3} \mathrm{mmol}\right)$ and DMF $\left.(7.6 \mathrm{~g}, 8.0 \mathrm{~mL})\right]$.

Synthesis of poly[oligo(ethylene glycol) methyl ether methacrylate]-b-poly[(lauryl methacrylate)-co-(5,6-benzo-2-methylene-1,3-dioxepane)] (POEGMA-b-P(LMA-co$B M D O)$ ). A typical synthesis of $\mathrm{POEGMA}_{23}-b-\mathrm{P}\left(\mathrm{LMA}_{150}-c o-\mathrm{BMDO}\right)\left(\mathbf{O E G}_{\mathbf{2 3}}-\mathrm{L}_{150} \mathbf{B}\right)$ by RAFT dispersion polymerization at $15 \mathrm{wt} . \%$ solids and $f_{\mathrm{BMDO}, 0}=0.2($ BM1) was as follows: in a $40 \mathrm{~mL}$ vial, fitted with a rubber septum and a magnetic stirring bar, a mixture of LMA $\left(0.514 \mathrm{~g}, 2.02 \times 10^{-3} \mathrm{~mol}\right), \mathrm{BMDO}\left(0.080 \mathrm{~g}, 4.91 \times 10^{-1} \mathrm{mmol}\right), \mathrm{T} 21 \mathrm{~s}$ initiator $\left(0.6 \mathrm{mg}, 2.78 \times 10^{-3} \mathrm{mmol}\right.$, dissolved at $0.1 \% \mathrm{w} / \mathrm{v}$ in DMF $)$ and POEGMA 23 macro-CTA $\left(0.101 \mathrm{~g}, 1.37 \times 10^{-2} \mathrm{mmol}\right.$; macro-CTA/initiator molar ratio $\left.=5.0\right)$ in anhydrous DMF (3.8 g, $4.0 \mathrm{~mL}$ ) was degassed by argon bubbling for at least $15 \mathrm{~min}$ and then immersed in a preheated oil bath at $90{ }^{\circ} \mathrm{C}$ for $24 \mathrm{~h}$. Determination of LMA conversion and colloidal characteristics of the nanoparticles as well as purification of the copolymers were performed as for $\mathbf{O E G}_{\mathbf{2 3}}-\mathbf{L}_{\mathbf{1 5 0}} \mathbf{M P}$.

The same procedure was performed with: $f_{\mathrm{BMDO}, 0}=0.4$ (BM2) [LMA (0.501 g, $\left.1.97 \times 10^{-3} \mathrm{~mol}\right), \mathrm{BMDO}\left(0.241 \mathrm{~g}, 1.48 \times 10^{-3} \mathrm{~mol}\right), \mathrm{T} 21 \mathrm{~s}$ initiator $\left(0.6 \mathrm{mg}, 2.78 \times 10^{-}\right.$ ${ }^{3} \mathrm{mmol}$, dissolved at $0.1 \% \mathrm{w} / \mathrm{v}$ in DMF) and POEGMA 23 macro-CTA $(0.096 \mathrm{~g}, 1.30 \times$ $\left.10^{-2} \mathrm{mmol}\right)$ and DMF (4.6 g, $\left.\left.4.9 \mathrm{~mL}\right)\right] ; f_{B \mathrm{MDO}, 0}=0.6(\mathbf{B M 3})\left[\mathrm{LMA}\left(0.503 \mathrm{~g}, 1.98 \times 10^{-}\right.\right.$ 
$\left.{ }^{3} \mathrm{~mol}\right)$, BMDO (0.482 g, $\left.2.96 \times 10^{-3} \mathrm{~mol}\right), \mathrm{T} 21 \mathrm{~s}$ initiator $\left(0.6 \mathrm{mg}, 4.17 \times 10^{-3} \mathrm{mmol}\right.$, dissolved at $0.1 \% \mathrm{w} / \mathrm{v}$ in DMF) and POEGMA 23 macro-CTA $\left(0.099 \mathrm{~g}, 1.34 \times 10^{-2}\right.$ $\mathrm{mmol})$ and DMF $(6.1 \mathrm{~g}, 6.4 \mathrm{~mL})] ; f_{B \mathrm{MDO}, 0}=0.7(\mathbf{B M 4})\left[\mathrm{LMA}\left(0.504 \mathrm{~g}, 1.98 \times 10^{-3}\right.\right.$ $\mathrm{mol})$, BMDO $\left(0.805 \mathrm{~g}, 4.94 \times 10^{-3} \mathrm{~mol}\right), \mathrm{T} 21 \mathrm{~s}$ initiator $\left(0.6 \mathrm{mg}, 2.78 \times 10^{-3} \mathrm{mmol}\right.$, dissolved at $0.1 \% \mathrm{w} / \mathrm{v}$ in DMF) and POEGMA 23 macro-CTA $\left(0.098 \mathrm{~g}, 1.32 \times 10^{-2}\right.$ mmol) and DMF (7.6 g, 8.0 mL)].

Synthesis of poly[oligo(ethylene glycol) methyl ether methacrylate]-b-poly[(lauryl methacrylate)-co-(2-methylene-1,3-dioxepane)] (POEGMA-b-P(LMA-co-MDO)). A typical synthesis of POEGMA $23-b-\mathrm{P}\left(\mathrm{LMA}_{150}-c o-\mathrm{MDO}\right)\left(\mathbf{O E G}_{23}-\mathbf{L}_{150} \mathbf{M}\right)$ by RAFT dispersion polymerization at $15 \mathrm{wt} . \%$ solids with $f_{\mathrm{MDO}, 0}=0.2$ (M1) was as follows: in a $40 \mathrm{~mL}$ vial, fitted with a rubber septum and a magnetic stirring bar, a mixture of LMA $\left(0.532 \mathrm{~g}, 2.09 \times 10^{-3} \mathrm{~mol}\right), \mathrm{MDO}\left(0.059 \mathrm{~g}, 5.18 \times 10^{-1} \mathrm{~mol}\right), \mathrm{T} 21 \mathrm{~s}$ initiator $(0.6 \mathrm{mg}, 2.78$ $\times 10^{-3} \mathrm{mmol}$, dissolved at $0.1 \% \mathrm{w} / \mathrm{v}$ in DMF) and POEGMA23 macro-CTA $(0.095 \mathrm{~g}$, $1.28 \times 10^{-2} \mathrm{mmol}$; macro-CTA/initiator molar ratio $\left.=5.0\right)$ in anhydrous DMF $(3.7 \mathrm{~g}$, $3.9 \mathrm{~mL}$ ) was degassed by argon bubbling for at least $15 \mathrm{~min}$ and then immersed in a preheated oil bath at $90{ }^{\circ} \mathrm{C}$ for $24 \mathrm{~h}$. Determination of LMA conversion and colloidal characteristics of the nanoparticles as well as purification of the copolymers were performed as for $\mathbf{O E G}_{23}-\mathbf{L}_{150} \mathbf{M P}$.

The same procedure was performed with $f_{\mathrm{MDO}, 0}=0.4$ (M2) [LMA $(0.520 \mathrm{~g}, 2.05 \times$ $\left.10^{-3} \mathrm{~mol}\right), \operatorname{MDO}\left(0.150 \mathrm{~g}, 1.32 \times 10^{-3} \mathrm{~mol}\right), \mathrm{T} 21 \mathrm{~s}$ initiator $\left(0.6 \mathrm{mg}, 2.78 \times 10^{-3} \mathrm{mmol}\right.$, dissolved at $0.1 \% \mathrm{w} / \mathrm{v}$ in DMF) and POEGMA 23 macro-CTA $\left(0.098 \mathrm{~g}, 1.32 \times 10^{-2}\right.$ $\mathrm{mmol})$ and DMF $(4.3 \mathrm{~g}, 4.5 \mathrm{~mL})], f_{\mathrm{MDO}, 0}=0.6(\mathrm{M3})\left[\mathrm{LMA}\left(0.510 \mathrm{~g}, 2.01 \times 10^{-3} \mathrm{~mol}\right)\right.$, 
MDO $\left(0.340 \mathrm{~g}, 2.98 \times 10^{-3} \mathrm{~mol}\right), \mathrm{T} 21 \mathrm{~s}$ initiator $\left(0.6 \mathrm{mg}, 2.78 \times 10^{-3} \mathrm{mmol}\right.$, dissolved at $0.1 \% \mathrm{w} / \mathrm{v}$ in DMF $)$ and POEGMA 23 macro-CTA $\left(0.095 \mathrm{~g}, 1.28 \times 10^{-2} \mathrm{mmol}\right)$ and DMF $(5.5 \mathrm{~g}, 5.8 \mathrm{~mL})]$ and $f_{\mathrm{MDO}, 0}=0.7(\mathrm{M} 4)\left[\operatorname{LMA}\left(0.504 \mathrm{~g}, 1.98 \times 10^{-3} \mathrm{~mol}\right), \mathrm{MDO}(0.524\right.$ $\left.\mathrm{g}, 4.60 \times 10^{-3} \mathrm{~mol}\right), \mathrm{T} 21 \mathrm{~s}$ initiator $\left(0.6 \mathrm{mg}, 4.17 \times 10^{-3} \mathrm{mmol}\right.$, dissolved at $0.1 \% \mathrm{~W} / \mathrm{v}$ in DMF) and POEGMA 23 macro-CTA (0.099 g, $\left.1.34 \times 10^{-2} \mathrm{mmol}\right)$ and DMF (6.4 g, 6.8 $\mathrm{mL})]$.

\subsection{Degradation procedures}

2.4.1. Polymer degradation. In a $5 \mathrm{~mL}$ vial, $50 \mathrm{mg}$ of purified copolymer was dissolved in $2.5 \mathrm{~mL}$ of THF. After solubilization, $2.5 \mathrm{~mL}$ of potassium hydroxide solution (KOH, 5 wt.\%) in $\mathrm{MeOH}$ was added. The cloudy mixture was stirred at room temperature. Samples $(1 \mathrm{~mL})$ were periodically withdrawn, immediately dried under vacuum and mixed with $2 \mathrm{~mL}$ of chloroform, allowing salts filtration using a $0.2 \mu \mathrm{m}$ PTFE filter. After filtration, the organic phase was washed three times with $\mathrm{HCl}(1 \mathrm{~mL}$, 1 mol.L $\left.{ }^{-1}\right)$. The organic solvent was then removed under reduced pressure and the degradation products were analyzed by SEC with 0.1 vol.\% TFA in the eluent.

2.4.2. Nanoparticle degradation. In a $40 \mathrm{~mL}$ vial were mixed an aqueous suspension of nanoparticles and an equal volume of aqueous potassium hydroxide ( $\mathrm{KOH}, 5$ wt.\%). The vial was placed in an orbital shaker (IKA KS4000i control, $37^{\circ} \mathrm{C}, 90 \mathrm{rpm}$ ) and samples were withdrawn at different intervals and lyophilized. $2 \mathrm{~mL}$ of chloroform was then added to each vial allowing salts filtration by using a $0.2 \mu \mathrm{m}$ PTFE filter. After filtration, the organic phase was washed three times with $\mathrm{HCl}\left(1 \mathrm{~mL}, 1 \mathrm{~mol} . \mathrm{L}^{-1}\right)$. The 
organic solvent was then removed under reduced pressure and the degradation products were analyzed by SEC with 0.1 vol.\% TFA in the eluent.

\subsection{Transfer procedures to water}

2.5.1. Dialysis against water. A suspension of nanoparticles was directly poured into a pre-wetted dialysis bag (MWCO 3500, RC membrane) and then dialyzed against water. Water was changed twice a day for three days. The same procedure was also performed except the nanoparticle suspension was diluted 20 times in DMF before dialysis.

2.5.2. Dialysis with an intermediate solvent. A suspension of nanoparticles was directly poured into a pre-wetted dialysis bag (MWCO 3500, RC membrane) and then dialyzed against acetone. Acetone was changed twice a day for three days. After dialysis, the acetone suspension of nanoparticles was transferred to another dialysis bag $(\mathrm{MWCO}=3500, \mathrm{RC}$ membrane $)$ and dialyzed against water. Water was changed twice a day for three days.

\subsection{Biological evaluation}

2.6.1 Cell culture. Human endothelial umbilical vein cells (HUVEC), embryonic murine fibroblast (NIH/3T3) and murine macrophage-monocyte cells (J774.A1) were purchased from American Type Culture Collection (ATCC) and maintained as recommended. Fetal Bovine Serum (FBS) was purchased from Gibco, PenicillinStreptomycin stabilized solution, Dulbecco's Modified Eagle Medium (DMEM) and Roswell Park Memorial Institute medium (RPMI)-1640 medium were purchased from Sigma-Aldrich and used as received. J774.A1 cells were grown in RPMI-1640 
supplemented with $10 \%$ FBS, penicillin $\left(50 \mathrm{U} \cdot \mathrm{mL}^{-1}\right)$ and streptomycin $\left(50 \mathrm{U} \cdot \mathrm{mL}^{-1}\right)$. NIH/3T3 and HUVEC cells were grown in DMEM high glucose supplemented with 10 $\%$ FBS, penicillin (50 U.mL $\left.\mathrm{mL}^{-1}\right)$ and streptomycin $\left(50 \mathrm{U} \cdot \mathrm{mL}^{-1}\right)$. Cells were maintained in a humid atmosphere at $37{ }^{\circ} \mathrm{C}$ with $5 \% \mathrm{CO}_{2}$.

2.6.2 Cell viability assay. In 96-well microtiter plates (TPP, Switzerland), cells were seeded (HUVEC: $2 \times 10^{4}$ cells $\mathrm{mL}^{-1}$, NIH/3T3: $4 \times 10^{4}$ cells $\mathrm{mL}^{-1}$, J774.A1: $2 \times 10^{4}$ cells $\left.\mathrm{mL}^{-1}\right)$ in $100 \mu \mathrm{L}$ of growth medium and preincubated for $24 \mathrm{~h}$ in incubator $\left(37^{\circ} \mathrm{C}\right.$ and $5 \% \mathrm{CO}_{2}$ ). After appropriate dilutions, $100 \mu \mathrm{L}$ of the copolymer nanoparticles (obtained after intermediate dialysis in acetone to remove remaining monomer, see part $3.3)$ in cell culture medium $\left(0.01,0.05,0.1\right.$ and $\left.0.5 \mathrm{mg} \cdot \mathrm{mL}^{-1}\right)$ was added over the cells and incubated for $72 \mathrm{~h}$. A MTT solution $\left(5 \mathrm{mg} \cdot \mathrm{mL}^{-1}\right)$ was prepared with phosphate buffered saline (PBS) and filtered with sterile filters $(0.2 \mu \mathrm{m})$. At the end of incubation period, $20 \mu \mathrm{L}$ of MTT solution was added to each well. After incubation $(1 \mathrm{~h}$ for HUVEC and J774.A1 cells, $1.5 \mathrm{~h}$ for NIH/3T3 cells), the medium was removed and $200 \mu \mathrm{L}$ of dimethylsulfoxide (DMSO) was then added to each well to dissolve the formazan crystals. The absorbance was then measured by a microplate reader (LAB Systems Original Multiscan MS) at $570 \mathrm{~nm}$. Cell viability was calculated as the absorbance ratio between treated and untreated control cells. All experiments were performed in triplicate to determine means and SD. 


\section{Results and Discussion}

\subsection{Design rationale}

Previous work in rROPISA was limited to the synthesis of non-aqueous suspensions of CKA-containing poly(lauryl methacrylate)- $b$-poly(benzyl methacrylate) (PLMA- $b$ PBzMA) nanoparticles in heptane to prevent early hydrolysis of CKA monomers/repeat units. ${ }^{[38,45]}$ Their hydrophobic PLMA stabilizing shell therefore prevents any subsequent transfer to aqueous media. In this context, we designed a simple two-step rROPISA system allowing for the synthesis of stable aqueous suspensions of degradable particles by first performing rROPISA in DMF as a water-miscible polar solvent, followed by transfer of the particles to water during which their colloidal properties were preserved.

The idea was to choose poly[oligo(ethylene glycol) methyl ether methacrylate] (POEGMA) as the solvophilic block given its solubility in both water and many polar organic solvents including DMF (Figure 2). Also, POEGMA is a well-known PEGbased polymer used in the biomedical field, owing to its biocompatibility and to the stealth properties it confers to nanoparticles or therapeutics. ${ }^{[39-43,46-48]}$ PLMA was selected as a solvophobic block according to its non-solubility in DMF and the ability of LMA to copolymerize with CKAs such as MPDL and BMDO.$^{[38]}$ These two aromatic ring-containing CKAs were first tested before investigating the use of MDO, which has the same structure as polycaprolactone, a well-known polymer approved for use in humans. ${ }^{[49]}$ 


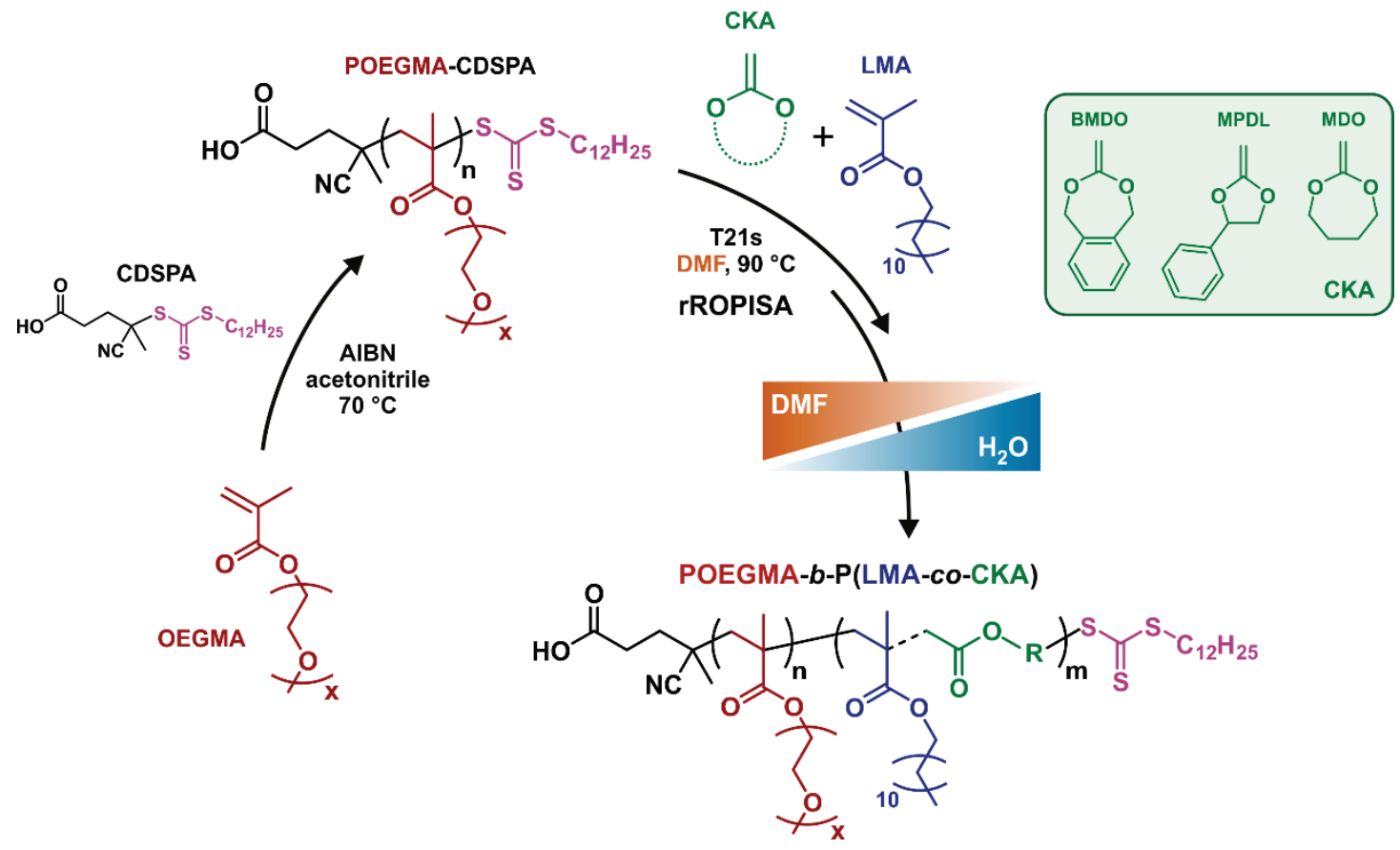

Figure 2. RAFT-mediated synthesis of poly[oligo(ethylene glycol) methyl ether methacrylate)] (POEGMA) chain transfer agent followed by radical ring-opening copolymerization-induced self-assembly (rROPISA) in DMF at $90^{\circ} \mathrm{C}$ of lauryl methacrylate (LMA) and cyclic ketene acetals (CKAs), followed by transfer to water to produce aqueous suspensions of POEGMA- $b$ P(LMA-co-CKA) (OEG $\left.\mathbf{G}_{\mathbf{m}}-\mathbf{L}_{\mathbf{n}} \mathbf{C K A}\right)$ diblock copolymer nanoparticles.

\subsection{Application to the three main CKAs}

3.2.1 Application to MPDL. Well-defined POEGMA ${ }_{23}\left(M_{\mathrm{n}, \mathrm{SEC}}=7400\right.$ g.mol ${ }^{-1}, Ð=$

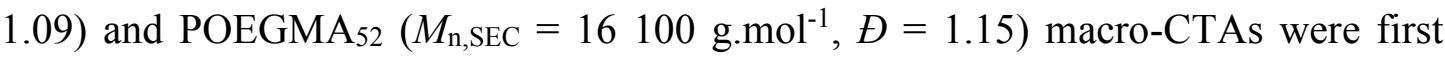
synthesized by RAFT solution polymerization of OEGMA in acetonitrile at $70{ }^{\circ} \mathrm{C}$ for $5 \mathrm{~h}$ using CDSPA as a CTA and AIBN as a radical initiator (Table S1, Figure S1).

The POEGMA23 macro-CTA was then chain-extended by copolymerization of LMA (targeted $\left.D P_{\mathrm{n}, \mathrm{PLMA}}=150\right)$ with variable initial amounts of MPDL $\left(f_{\mathrm{MPDL}, 0}=0\right.$ 0.7) at $15 \mathrm{wt} . \%$ solids in $\mathrm{DMF}$ at $90{ }^{\circ} \mathrm{C}$ in the presence of $\mathrm{T} 21 \mathrm{~s}$ as a radical initiator (OEG23-L150MP, MP0-MP4, Figure 2). After 24 h, high monomer conversions ( 80 $90 \%)$ were obtained except with MP4 $\left(f_{\text {MPDL }, 0}=0.7\right)$, for which the polymerization 
kinetics was slower (Table S2 and Figure 3a). Linear evolutions of $M_{\mathrm{n}}$ values with conversion and reasonably low dispersities $(~ Ð=1.2-1.4$ below $50 \%$ conversion) were obtained for all copolymerizations (Figure 3b), with no noticeable impact of the presence of MPDL when compared to MP0 $\left(f_{\mathrm{MPDL}, 0}=0\right)$. 
(a)

$\begin{array}{ll}\mathrm{MP0}\left(F_{\mathrm{MPDL}}=0\right) & \\ \diamond \mathrm{MP1}\left(F_{\mathrm{MPDL}}=0.03\right) & \triangle \mathrm{MP3}\left(F_{\mathrm{MPDL}}=0.09\right) \\ \mathrm{MP2}\left(F_{\mathrm{MPDL}}=0.07\right) & \triangle \mathrm{MP4}\left(F_{\mathrm{MPDL}}=0.20\right)\end{array}$

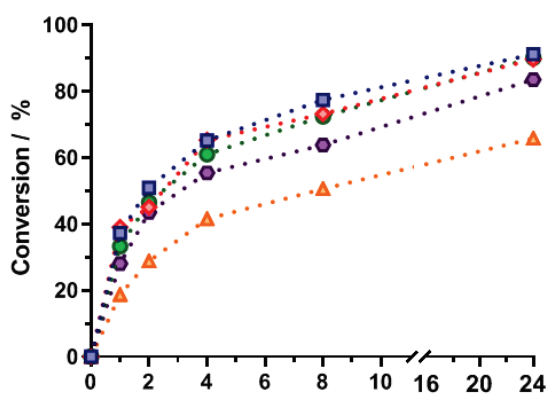

(b)
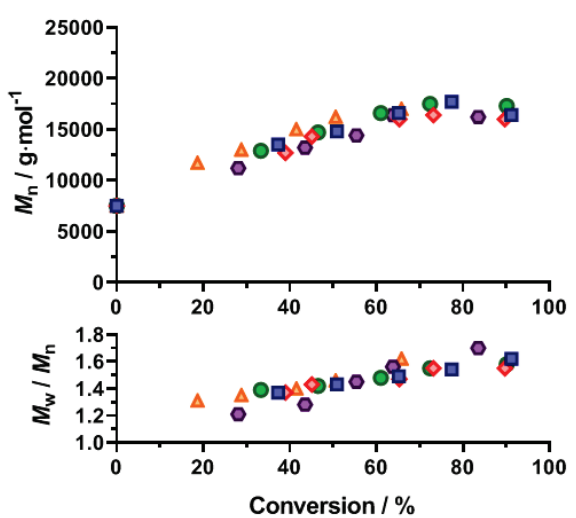

(d)

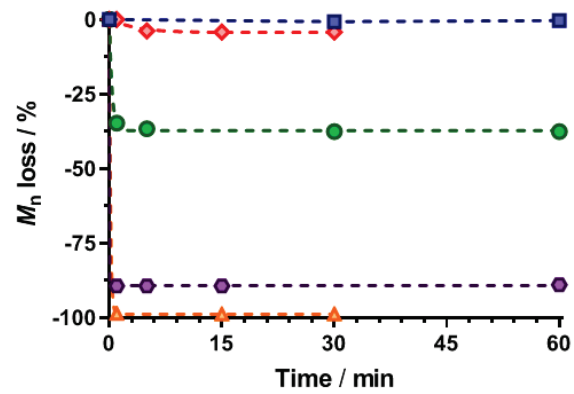

(c)
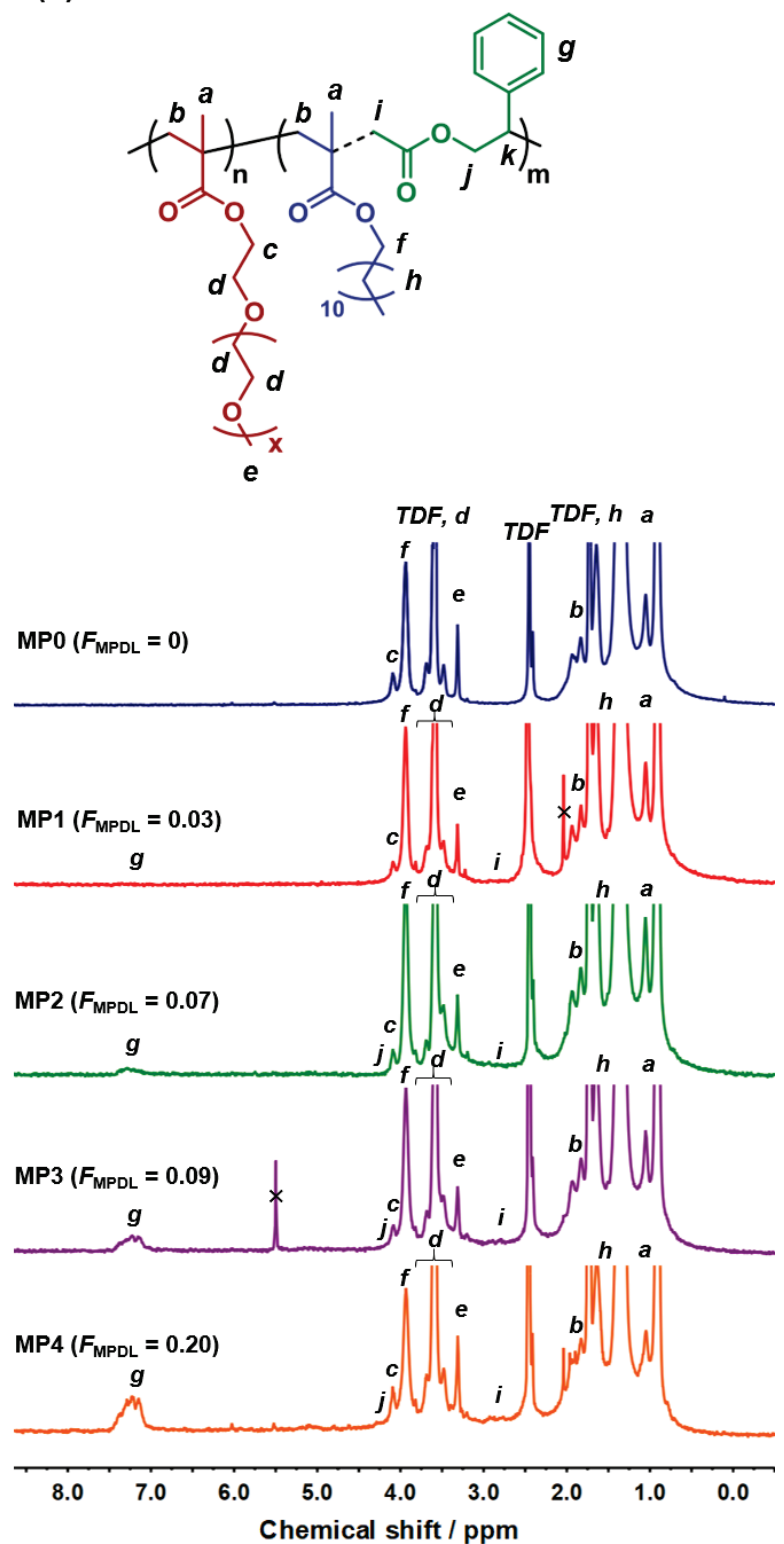

Figure 3. Synthesis of $\mathbf{O E G}_{23}-\mathbf{L}_{\mathbf{1 5 0}}$ MP copolymer nanoparticles (MP0-MP4) by RAFTmediated dispersion copolymerization of LMA and MPDL from a POEGMA ${ }_{23}$ macro-CTA in

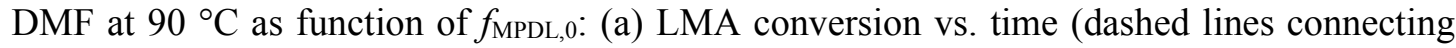
data points are guides for the eye only); (b) $M_{\mathrm{n}}$ and dispersity $\left(M_{\mathrm{w}} / M_{\mathrm{n}}\right)$ of the copolymers vs. LMA conversion determined by SEC; (c) ${ }^{1} \mathrm{H}$ NMR spectra in TDF of the copolymers in the 0 $8.5 \mathrm{ppm}$ region and (d) evolution with time of their $M_{\mathrm{n}}$ loss during degradation under accelerated conditions (dashed lines represent the exponential one phase decay fits).

The structure of POEGMA- $b$-P(LMA-co-MPDL) copolymers was confirmed by ${ }^{1} \mathrm{H}$ NMR spectroscopy (Figure 3c), with in particular, the successful insertion of MPDL as 
shown by the aromatic protons $g$. Their integration increased with $f_{\mathrm{MPDL}, 0}$ and gave molar fractions in the copolymer, $F_{\mathrm{MPDL}}$, ranging from 0 to 0.20 (Table S2). The presence of ester groups in the copolymer was confirmed by hydrolytic degradation under accelerated conditions (THF/MeOH, KOH 2.5 wt.\%). While MP0 $\left(f_{\mathrm{MPDL}, 0}=0\right)$ let the $M_{\mathrm{n}}$ unchanged, MP1-MP4 $\left(f_{\mathrm{MPDL}, 0}=0.2-0.7\right)$ copolymers gave a decrease in $M_{\mathrm{n}}$ (Figure 3d), as shown by the shifts of the SEC chromatograms towards lower $M_{\mathrm{n}}$ values (Figure S2). As expected, the higher $F_{\mathrm{MPDL}}\left(\right.$ or $f_{\mathrm{MPDL}, 0}$ ), the lower the final $M_{\mathrm{n}}$ after degradation, that reached $25000,13100,2700$ and $200 \mathrm{~g} \cdot \mathrm{mol}^{-1}$ for $F_{\mathrm{MPDL}}=0.03,0.07$, 0.09 and 0.20 , respectively (Table S3). Those values are in the same order of magnitude than the theoretical ones for the highest amounts of MPDL (Table S3). The discrepancy at low MPDL contents may be can be explained by the non-negligible amount of closed MPDL units in the copolymer, as already seen with this CKA. ${ }^{[50]}$

The onset of the micellar nucleation and the formation of particles occurred after 0.5-1 h, as evidenced by the change in appearance of the polymerization medium from transparent to opalescent. After the polymerizations, stable suspensions of POEGMA$b$-P(LMA-co-MPDL) nanoparticles in DMF were obtained exhibiting average intensity-diameters $\left(D_{\mathrm{z}}\right)$ in the $72-109 \mathrm{~nm}$ range and particle size distributions (PSD) all below 0.1, indicating narrowly dispersed nanoparticles (Table S2).

The OEG23-L150MP nanoparticles were then transferred to water through a simple dialysis step. Direct dialysis against water gave stable nanoparticle suspensions only for $F_{\mathrm{MPDL}} \leq 0.07$, likely because of the strong hydrophobicity of unreacted MPDL that altered the colloidal stability. However, when all nanoparticles were diluted 1:20 with 
DMF prior dialysis, highly stable nanoparticles with narrow PSD (0.01-0.03) were

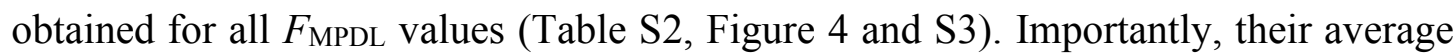
diameters were preserved after dialysis, with however a noticeable increase in the nanoparticles' size for high MPDL contents (Figure 4a-e). TEM experiments revealed the formation of nanoparticles with spherical morphology (Figure $4 \mathrm{f}-\mathrm{o}$ ). Their average diameters and size distributions were in good agreement with DLS data except for the copolymer with the highest amount of MPDL whose PSD was already broad according to DLS, presumably due to the presence of micro-particle aggregates during TEM sample preparation. 
(a)
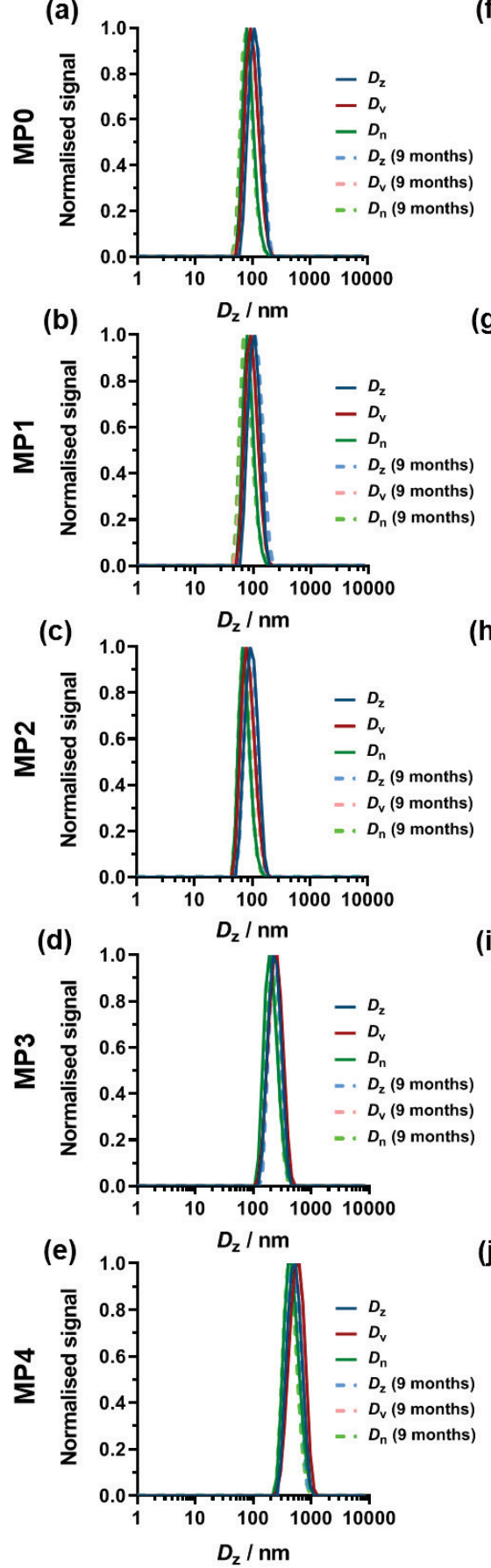

(f)

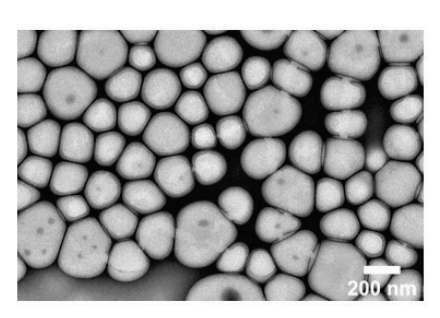

(g)

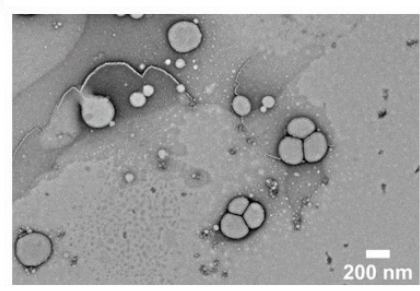

(h)

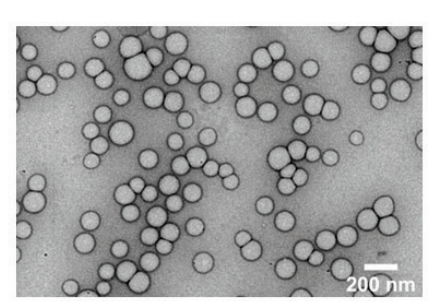

(i)

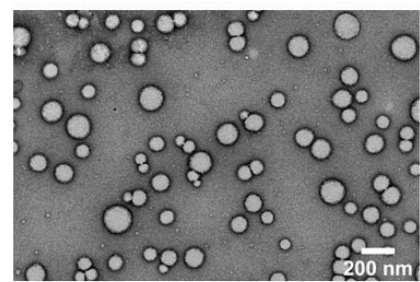

(j)

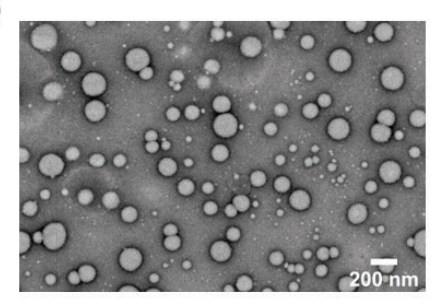

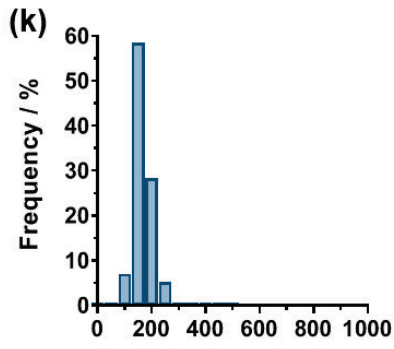

(I)

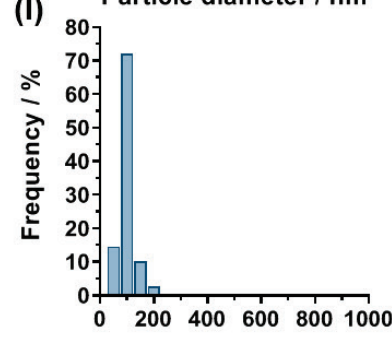

(m) Particle diameter $/ \mathrm{nm}$
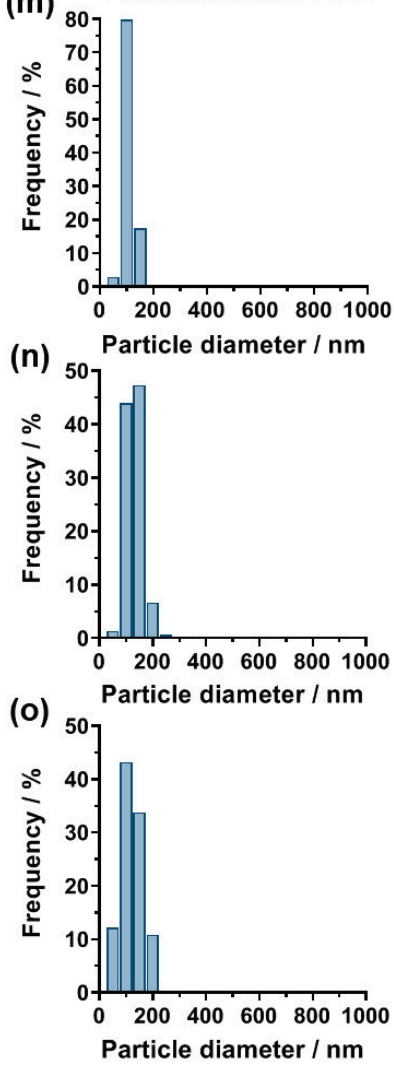

Figure 4. Colloidal characteristics of $\mathbf{O E G}_{23}-\mathbf{L}_{150} \mathbf{M P}$ nanoparticles MP0-MP4 after a 1:20 dilution in DMF and dialysis against water: (a-e) average diameters from DLS reported in number $\left(D_{\mathrm{n}}\right)$, volume $\left(D_{\mathrm{v}}\right)$ and intensity $\left(D_{\mathrm{z}}\right)$ distribution after formulation and after 9 months; $(\mathrm{f}-\mathrm{j})$ representative TEM images and $(\mathrm{k}-\mathrm{o})$ particle size distributions $(\mathrm{n}=75-800)$. TEM data $\left(D_{\mathrm{n}}, D_{\mathrm{w}}, D_{\mathrm{z}}\right.$, and PDI) are in Table $\mathrm{S} 4$. 
All nanoparticles also exhibited very high colloidal stability with no or little variation of their average diameters or their dispersity $(\mathrm{PSD}=0.01-0.03)$ after at least 9 months (Figure 4a-e), which demonstrated the robustness of the 2-step rROPISA process for the preparation of stable aqueous suspensions of CKA-containing nanoparticles.

Similar rROPISA experiments were then performed with the longest macro-CTA $\left(\right.$ POEGMA $\left._{52}\right)$ to potentially improve the preservation of the nanoparticles' colloidal properties at high MPDL contents upon their transfer to water, as suggested by its superior stabilization properties during rROPISA in heptane. ${ }^{[51]}$ Copolymerizations of LMA (targeted $\left.D P_{\mathrm{n}, \mathrm{PLMA}}=300\right)$ and MPDL $\left(f_{\mathrm{MPDL}, 0}=0-0.7\right)$ were performed in DMF under the same experimental conditions as previously described in order to produce OEG52-L300MP copolymer nanoparticles (MP5-MP9, Table S2). Very similar results in terms of conversions $(70-88 \%)$ and control of the polymerizations $\left(M_{\mathrm{n}}=37.0-22.9\right.$ kg.mol $\left.{ }^{-1}, Ð=1.54-1.86\right)$ were obtained, with however an overall increase in size of the nanoparticles $\left(D_{z}=113-168 \mathrm{~nm}, \mathrm{PSD}=0.10-0.22\right)$. Interestingly, the MPDL contents were also mostly higher (Table S2, Figure S4a), resulting in more pronounced hydrolytic degradation under accelerated conditions for OEG52-L300MP copolymers than the OEG23-L150MP counterparts for the same $f_{\mathrm{MPDL}, 0}$ value (Figure S2 and S4b). It also resulted in a slightly better agreement between predicted and experimental $M_{\mathrm{n}}$ values after degradation (Table S5).

Dialysis of OEG52-L300MP nanoparticles against water also led to stable aqueous suspensions of spherical nanoparticles with narrow PSD as shown by DLS and TEM (Table S2 and S4, Figure S3 and S5). Interestingly, conversely to OEG23-L150MP 
nanoparticles, they exhibited a much better preservation of their colloidal characteristics even for nanoparticles with the highest MPDL contents (Table S2 and Figure 5), together with a better agreement between average diameters determined by DLS and TEM.
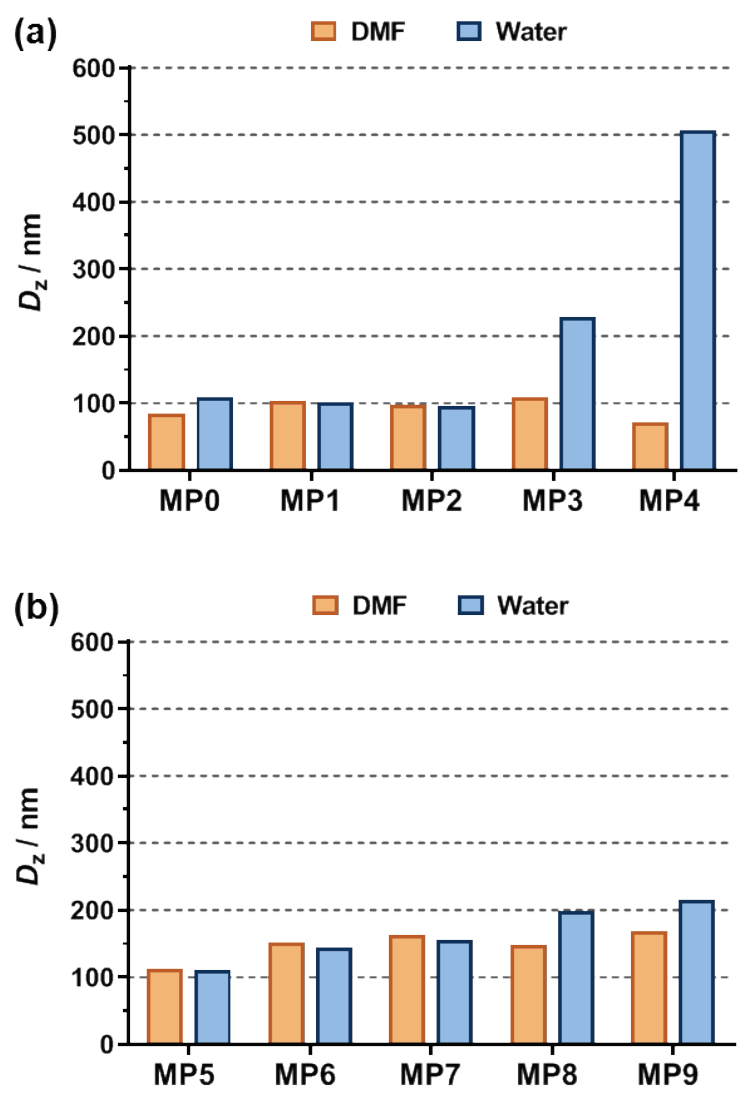

Figure 5. Intensity-average diameters ( $\left.D_{\mathrm{z}}\right)$ of: (a) $\mathbf{O E G}_{\mathbf{2 3}}-\mathbf{L}_{\mathbf{1 5 0}} \mathbf{M P}$ (MP0-MP4) and (b) $\mathbf{O E G}_{\mathbf{5 2}}$ L300MP (MP5-MP9) nanoparticles in DMF (orange bars) and after a 1:20 dilution in DMF followed by dialysis against water (blue bars).

3.2.2 Application to BMDO. The 2-step rROPISA process was then successfully applied to BMDO, which is still one of the most popular CKAs used in rROP. OEG23$\mathbf{L}_{150}$ B copolymers nanoparticles were obtained by chain-extension of POEGMA 23 macro-CTA by copolymerization of LMA and BMDO $\left(f_{\mathrm{BMDO}, 0}=0.2-0.7\right)$ under the 
same experimental conditions as for OEG23-L150MP copolymers (Figure S6 and Table S6). In general, very similar results were obtained compared to MPDL. However, a better control of the polymerizations was achieved $(\nexists=1.23-1.50)$, together with a slight increase in the BMDO content in the obtained copolymers (Table S6).

Degradation of OEG23-L150B copolymers under accelerated conditions confirmed their tunable degradability as function of $f_{\mathrm{BMDO}, 0}$ (Table S7, Figure S6b and S7a-d). The degradation was very similar to that of $\mathbf{O E G} \mathbf{2 3}-\mathbf{L} \mathbf{1 5 0} \mathbf{M P}$ copolymers with nonetheless a much more pronounced decrease in $M_{\mathrm{n}}$ when $f_{\mathrm{BMDO}, 0}=0.4(-75 \%$ vs. $-38 \%)$ owing to its higher $\mathrm{BMDO}$ content $\left(F_{\mathrm{BMDO}}=0.15\right.$ vs. $\left.F_{\mathrm{MPDL}}=0.07\right)$.

Narrowly dispersed nanoparticles were also obtained (PSD $\leq 0.06$ ), but with smaller diameters $\left(D_{z}=53-78 \mathrm{~nm}\right)$ than MPDL-containing nanoparticles (Table S6). After diluted dialysis against water, very stable nanoparticles were obtained and with average diameters in the range $93-161 \mathrm{~nm}$ and excellent retention of their narrow PSD (Figure 6 and S3). Interestingly, no significant size increase was obtained for OEG23L150B nanoparticles with the highest amounts of BMDO, as they all remained below $200 \mathrm{~nm}$ in diameter (Figure S8a). The colloidal properties obtained by TEM were in good agreement with DLS measurements and also showed spherical morphologies (Figure 6). 

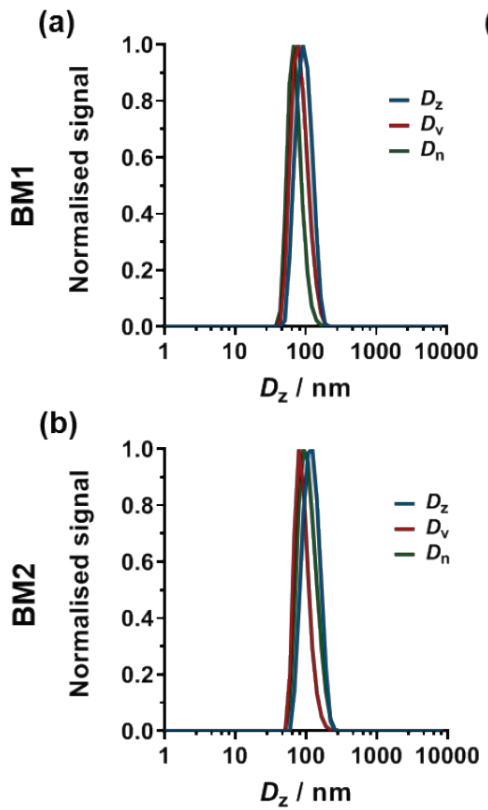

(c)

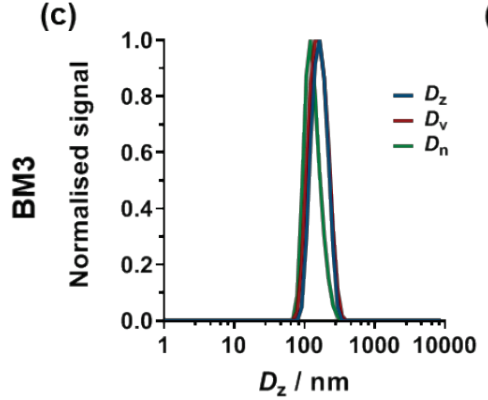

(d)

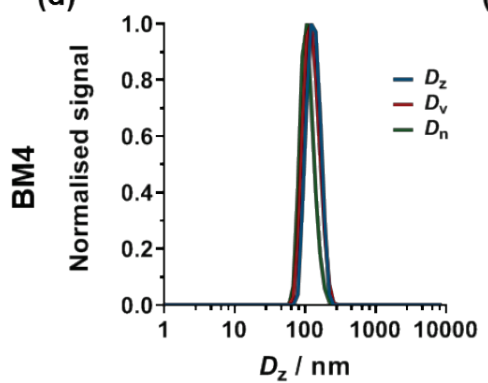

(e)
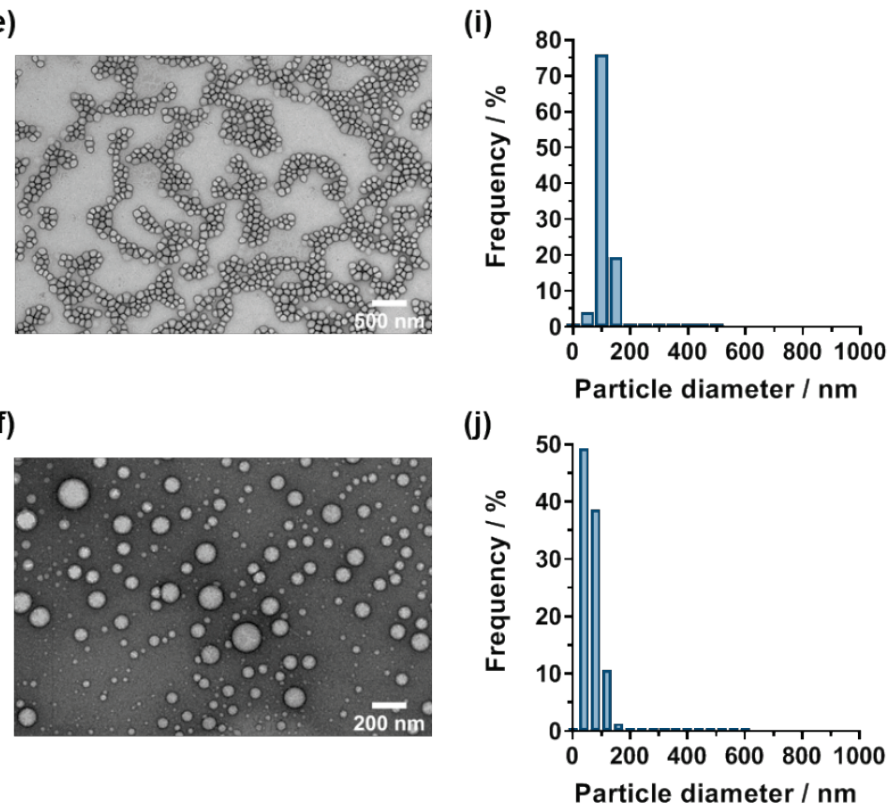

(g)

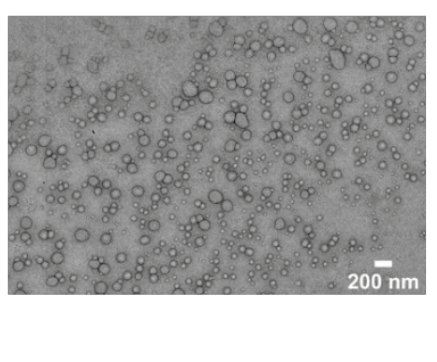

(h)

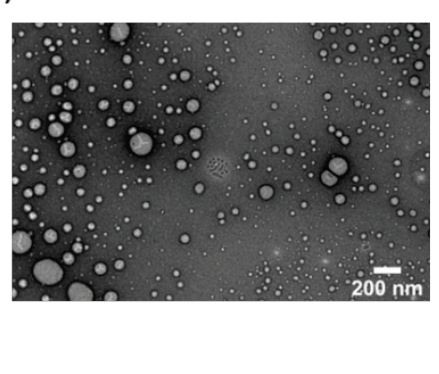

(j)

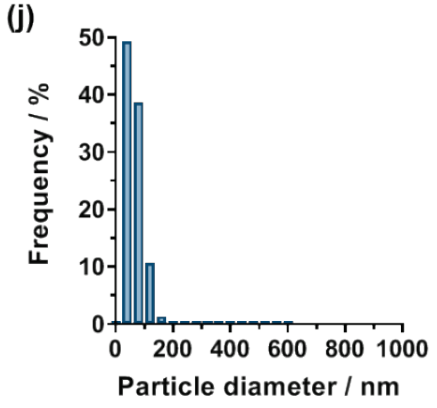

(k)

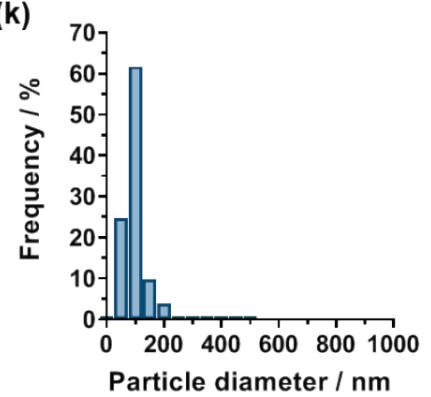

(l)

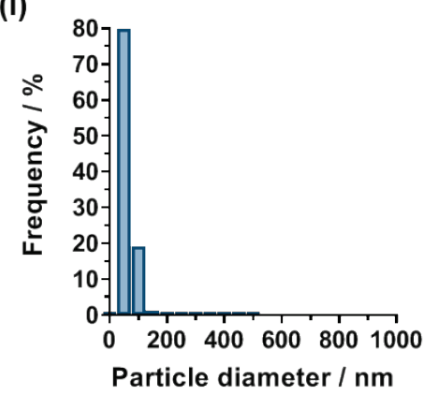

Figure 6. Colloidal characteristics of $\mathbf{O E G}_{23}-\mathbf{L}_{150} \mathbf{B}$ nanoparticles BM1-BM4 after a 1:20 dilution in DMF and dialysis against water: (a-d) average diameters from DLS reported in number $\left(D_{\mathrm{n}}\right)$, volume $\left(D_{\mathrm{v}}\right)$ and intensity $\left(D_{\mathrm{z}}\right)$ distribution after formulation; (e-h) representative TEM images and $(\mathrm{i}-1)$ particle size distributions $(\mathrm{n}=150-1200)$. TEM data $\left(D_{\mathrm{n}}, D_{\mathrm{w}}, D_{\mathrm{z}}\right.$, and PDI) are in Table S8.

3.2.3 Application to MDO. Even if rROPISA in heptane with MDO as a CKA was successful, it gave high dispersities up to 4 and thus a partial loss of control. ${ }^{[38]}$ Herein, rROPISA in DMF under similar conditions achieved a much better control of the 
copolymerization (Table S9) with $M_{\mathrm{n}}=14.1-19.2 \mathrm{~kg} \cdot \mathrm{mol}^{-1}$ and $Ð=1.57-1.80 .{ }^{1} \mathrm{H}$ NMR spectroscopy attested that $\mathbf{O E G} \mathbf{2 3}-\mathbf{L}_{\mathbf{1 5 0}} \mathbf{M}$ copolymers were synthesized (Figure S9a) with $F_{\mathrm{MDO}}=0.08-0.15$, depending on the initial comonomer feed.

All copolymers exhibited nearly complete degradation under accelerated conditions (Figure S9b) and excellent agreement with the predicted values (Table S10, Figure S7e-h), suggesting a very high proportion of open MDO. The same transfer procedure to water resulted in stable nanoparticles with spherical morphologies and narrow PSD as observed by DLS and TEM, except for $f_{\mathrm{MDO}, 0}=0.7$ (M4) that also gave a fraction of microparticles (Figure 7). Not only was there no significant variation in their average diameters after dialysis against water $\left(D_{z}=131-170 \mathrm{~nm}\right)$, but they were also fairly constant regardless of copolymer composition (Figure S3, S8b, Table S9). 
(a)
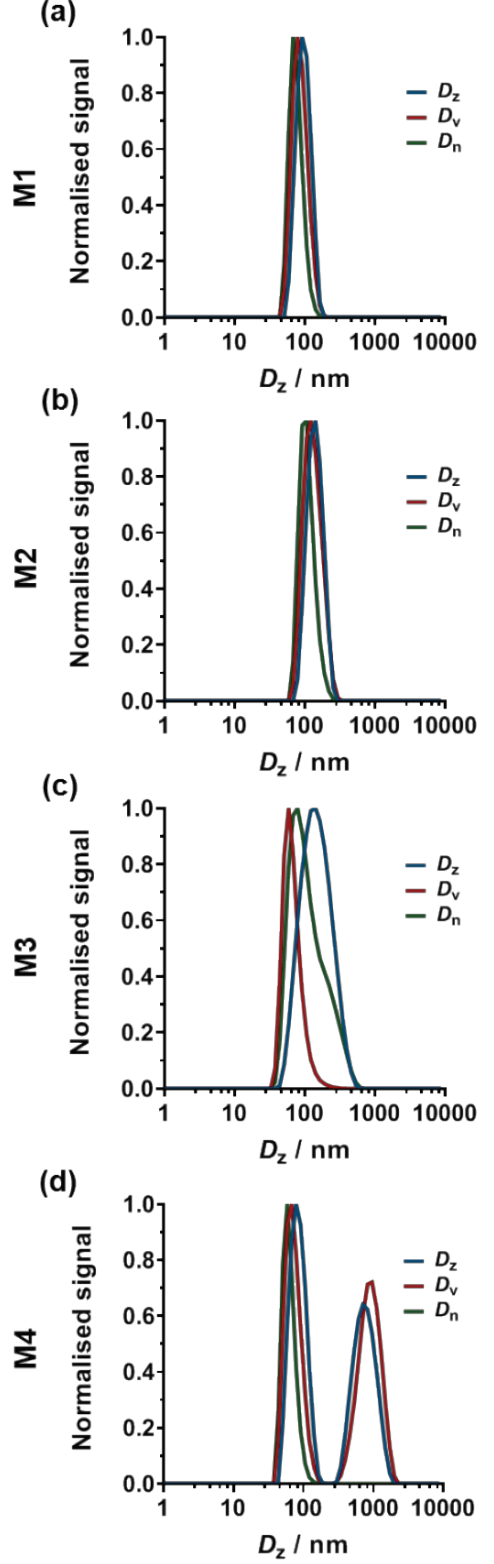

(e)

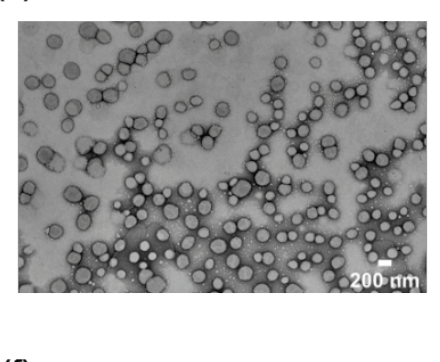

(f)

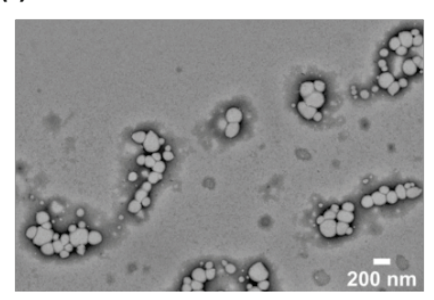

(g)

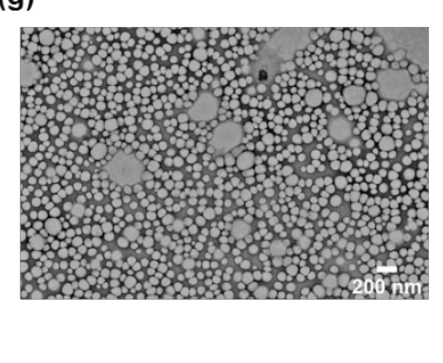

(h)

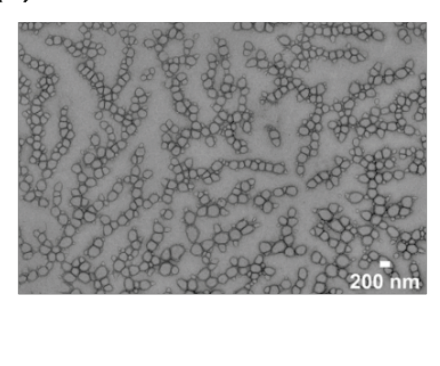

(i)
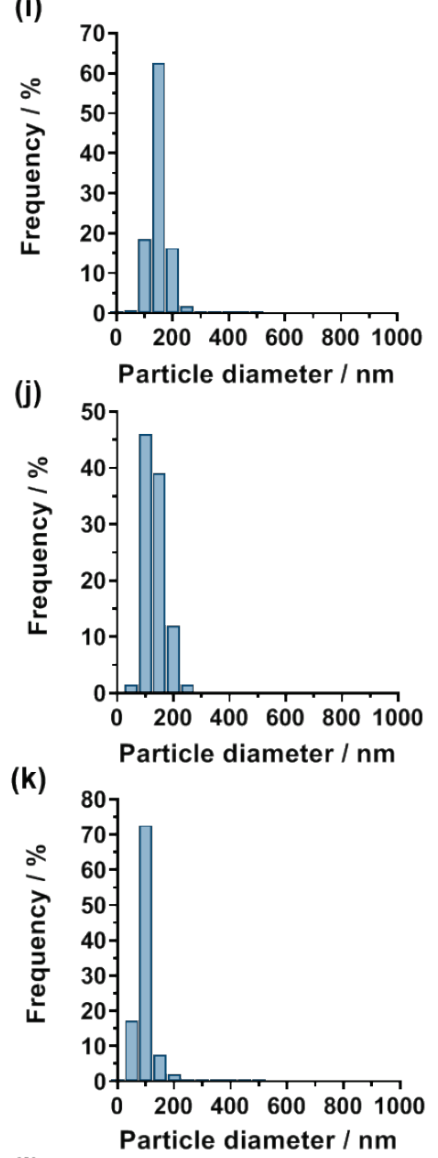

(l)

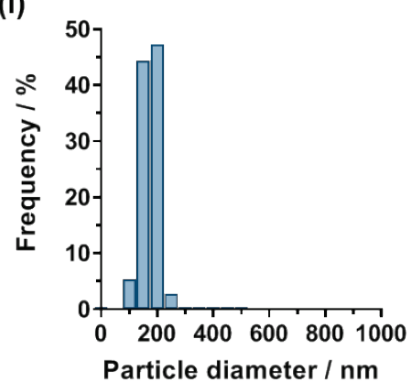

Figure 7. Colloidal characteristics of $\mathbf{O E G}_{23}-\mathbf{L}_{\mathbf{1 5 0}} \mathbf{M}$ nanoparticles M1-M4 after a 1:20 dilution in DMF and dialysis against water: (a-d) average diameters from DLS reported in number $\left(D_{\mathrm{n}}\right)$, volume $\left(D_{\mathrm{v}}\right)$ and intensity $\left(D_{\mathrm{z}}\right)$ distribution after formulation; $(\mathrm{e}-\mathrm{h})$ Representative TEM images and (i-1) particle size distributions $(\mathrm{n}=200-500)$. TEM data $\left(D_{\mathrm{n}}, D_{\mathrm{w}}, D_{\mathrm{z}}\right.$, and PDI) are in Table S11.

Importantly, OEG23-L150M nanoparticles in DMF could also be directly dialysed against water, thus maintaining their original concentrations as opposed to OEG23$\mathbf{L}_{150} M P$ and $\mathbf{O E G}_{23}-\mathbf{L}_{150} B$ nanoparticles that required a preliminary 1:20 dilution in 
DMF (Figure S10 and S11). OEG23-L150M nanoparticles exhibited colloidal stability as high as the other nanoparticles, well-preserved average diameters and narrow PSD $\left(D_{\mathrm{z}}=113-154 \mathrm{~nm}, \mathrm{PSD}=0.03-0.14\right)$ up to $F_{\mathrm{MDO}}=0.13($ Table S12).

\subsection{Optimization of the transfer to water}

The rROPISA process was then further optimized to allow all types of CKA-containing nanoparticles to be obtained in water without preliminary dilution, thus maximizing their aqueous concentrations. As previously hypothesized, we suspected that, for high $f_{\mathrm{CKA}, 0}$ values, unreacted MPDL/BMDO caused colloidal instability of $\mathbf{O E G} \mathbf{G}_{\mathbf{2 3}}-\mathbf{L}$ 150 MP and OEG23-L150B nanoparticles during their dialysis against water. This limitation was resolved by performing an intermediate dialysis against acetone. Not only the unreacted monomer was efficiently removed, as shown by ${ }^{1} \mathrm{H}-\mathrm{NMR}$ (Figure S12), but it also enabled the resultant nanoparticles to be successfully transferred to water by dialysis without dilution, even for the highest $f_{\mathrm{CKA}, 0}$ values (Figure S13). DLS measurements mostly showed little variation in diameters when passing from acetone to water and confirmed the excellent colloidal characteristics of $\mathbf{O E G}$ 23-L150MP and $\mathbf{O E G}$ 23-L150B nanoparticles in water in terms of size and particle size distribution (Figure 8 and Table S13). Average diameter in acetone was $\sim 140 \mathrm{~nm}$ (PSD $\sim 0.08$ ) while in water it reached $\sim 120 \mathrm{~nm}$ (PSD $\sim 0.11$ ). This procedure was also successfully applied to OEG52-L300MP and $\mathbf{O E G}_{23}-\mathrm{L}_{150} \mathrm{M}$ nanoparticles to show the versatility of the process. These two additional series of nanoparticles exhibited great colloidal stability with good 
preservation of their average diameters, despite slight broadening of the PSD for the highest CKA contents (Table S13).
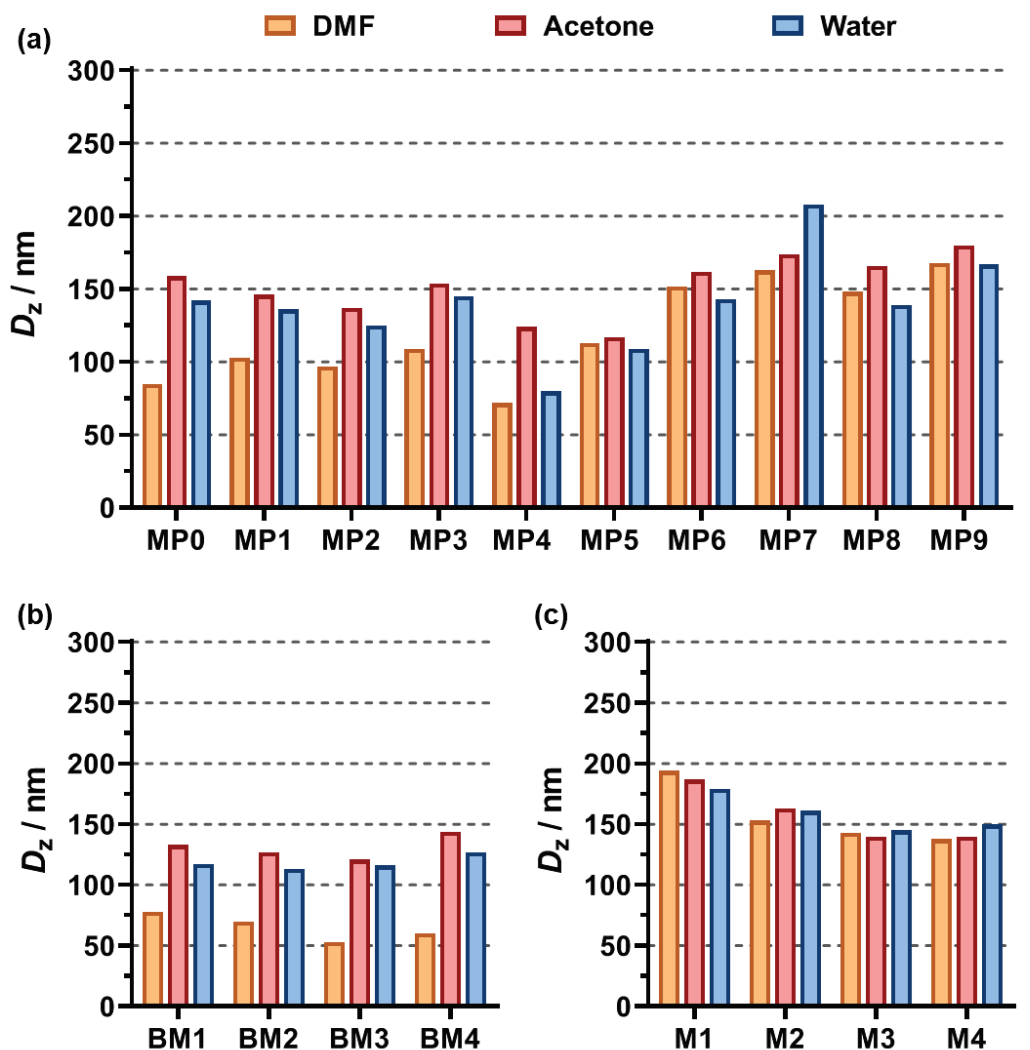

Figure 8. Intensity-average diameters of: (a) $\mathbf{O E G}_{23}-\mathbf{L}_{150} \mathbf{M P}$ (MP0-MP4) and $\mathbf{O E G}_{52}-\mathrm{L}_{300} \mathrm{MP}$ (MP5-MP9); (b) OEG 23-L $150_{15}$ (BM1-BM4) and (c) OEG OE-L $_{150}$ M (M1-M4) nanoparticles in DMF (orange bars), after direct dialysis against acetone (red bars) and followed by dialysis against water (blue bars).

Interestingly, cryo-TEM was used as a complementary technique to TEM and confirmed the spherical morphology for OEG23-L150MP and OEG52-L300MP nanoparticles (Figure S14), in good agreement with DLS data (Table S13) and TEM observations of their counterparts obtained without intermediate dialysis in acetone (Table S2). 


\subsection{Degradation of the nanoparticles}

After having shown the tunable hydrolytic degradation of the copolymers under accelerated conditions, degradation of the nanoparticles in aqueous suspension was investigated in $2.5 \mathrm{wt} . \% \mathrm{KOH}$ at $37^{\circ} \mathrm{C}$. Nanoparticles responded quickly to hydrolysis $(<24 \mathrm{~h})$ and exhibited tunable degradation as function of $F_{\text {CKA }}$ with decrease in $M_{\mathrm{n}}$ up to $>95 \%$ (Figure S15 and 9). Overall, the degradation kinetics and the final $M_{\mathrm{n}} \mathrm{s}$ after degradation of the different copolymer nanoparticles were similar to those of the corresponding free copolymers.

These results suggested that, regardless of the CKA used, important water uptake by the nanoparticles successfully occurred, resulting in significant degradation. It is also worth noting that this is the first time that extensive hydrolytic degradation of CKA-containing nanoparticles synthesized by polymerization in dispersed medium is reported. 

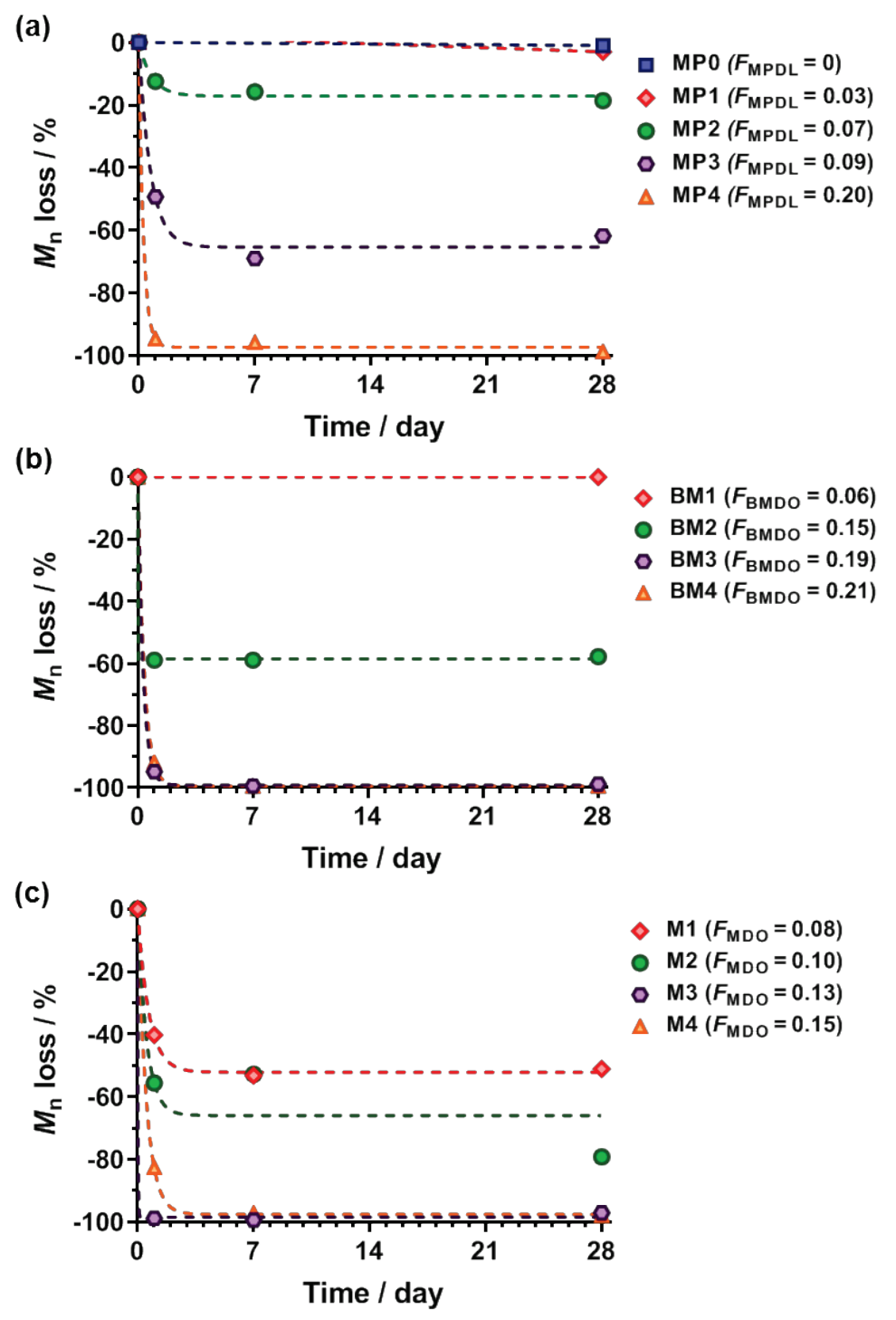

Figure 9. Evolution with time of the number-average molar mass $\left(M_{\mathrm{n}}\right)$ loss during degradation under accelerated conditions $(2.5 \% \mathrm{KOH}$ in water $)$ of $\mathbf{O E G}_{\mathbf{2 3}}-\mathbf{L}_{\mathbf{1 5 0}} \mathbf{C K A}$ copolymer nanoparticles with the molar fraction of CKA $\left(F_{\mathrm{CKA}}\right)$ in the copolymer: (a) $\mathbf{O E G}_{\mathbf{2 3}}-\mathbf{L}_{\mathbf{1 5 0}} \mathbf{M P}$ (MP0-MP4) copolymers nanoparticles $\left(F_{\mathrm{MPDL}}=0-0.20\right)$; (b) $\mathbf{O E G}_{\mathbf{2 3}}-\mathbf{L}_{\mathbf{1 5 0}} \mathbf{B M}$ (BM1-BM4) copolymers nanoparticles $\left(F_{\mathrm{BMDO}}=0.06-0.21\right)$ and (c) $\mathbf{O E G}_{\mathbf{2 3}}-\mathbf{L}_{\mathbf{1 5 0}} \mathbf{M}$ (M1-M4) copolymers nanoparticles $\left(F_{\mathrm{MDO}}=0.08-0.15\right)$. Dashed lines represent the exponential one phase decay fit.

\subsection{Cytocompatibility}

To show the broad applicability of these degradable vinyl copolymer nanoparticles, and for instance to consider their use for biomedical applications, their cytocompatibility was tested on three representative healthy cell lines via both cell viability assays and 
cell morphology observations. The cell lines used were: (i) murine macrophages (J774.A1), which are monocyte cells that play a key role in phagocytosis; (ii) human umbilical vein endothelial cells (HUVEC), which are widely used primary endothelial cells for in vitro studies of the vasculature and (iii) murine fibroblasts (NIH/3T3), which are one of the most commonly used fibroblast cell lines. Although there have been examples of cytocompatible CKA-containing copolymers and copolymers formulated into nanoparticles, ${ }^{[8,45,52,53]}$ the cytocompatibility of CKA-containing nanoparticles obtained by polymerization in dispersed media towards healthy cells has never been investigated.

Three representative libraries of nanoparticles were selected: (i) OEG23-L150MP and $\mathbf{O E G}_{23}-\mathbf{L}_{150} \mathrm{M}$, to investigate potential influence of the nature of the CKA and (ii) OEG52-L300MP, to evaluate the effect of the POEGMA block length. For each series of nanoparticles, the CKA content was varied $\left(f_{\mathrm{CKA}, 0}=0-0.7\right)$ to probe its effect on the cell viability. Note that $\mathbf{O E G} \mathbf{E}_{23}-\mathbf{L}_{150} \mathbf{B}$ nanoparticles were not tested due to their structural similarity to $\mathbf{O E G}_{\mathbf{2 3}}-\mathbf{L}_{\mathbf{1 5 0}} \mathbf{M P}$ nanoparticles. Overall, all types of nanoparticles exhibited cell viability in the $70-100 \%$ range up to $0.1 \mathrm{mg} \cdot \mathrm{mL}^{-1}$ for $\mathrm{NIH} / 3 \mathrm{~T} 3$ cells and up to $0.5 \mathrm{mg} \cdot \mathrm{mL}^{-1}$ for J774.A1 and HUVEC cells (Figure 10a-c). It should be noted that these relatively high concentrations do not reflect their expected use but would rather overexpress any cytotoxic effects arising from the copolymer structures or from their degradation products. Interestingly, despite their sensitivity to foreign materials due to their phagocytic functions resulting in engulfment of 
nanoparticles, macrophages (J774.A1 cells) exhibited cell viability greater than $80 \%$ for all nanoparticle concentrations.

(a) $\square 0.01 \mathrm{mg} \cdot \mathrm{mL}^{-1} \square 0.05 \mathrm{mg} \cdot \mathrm{mL}^{-1} \square 0.1 \mathrm{mg} \cdot \mathrm{mL}^{-1}$ (d)
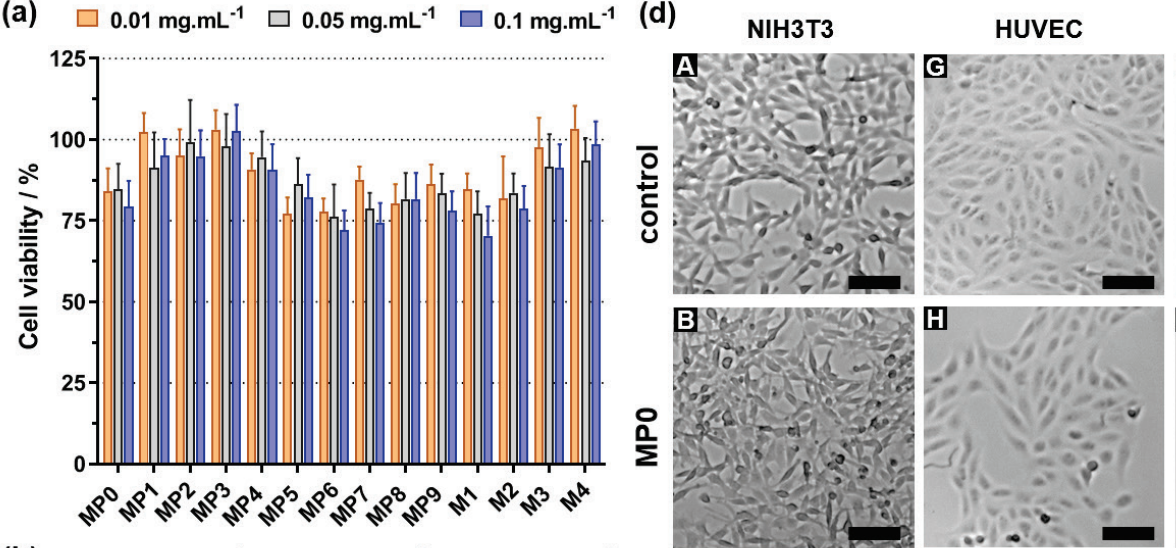

(b) $\square 0.01 \mathrm{mg} \cdot \mathrm{mL}^{-1} \quad \square 0.1 \mathrm{mg} \cdot \mathrm{mL}^{-1} \quad \square 0.5 \mathrm{mg} \cdot \mathrm{mL}^{-1}$
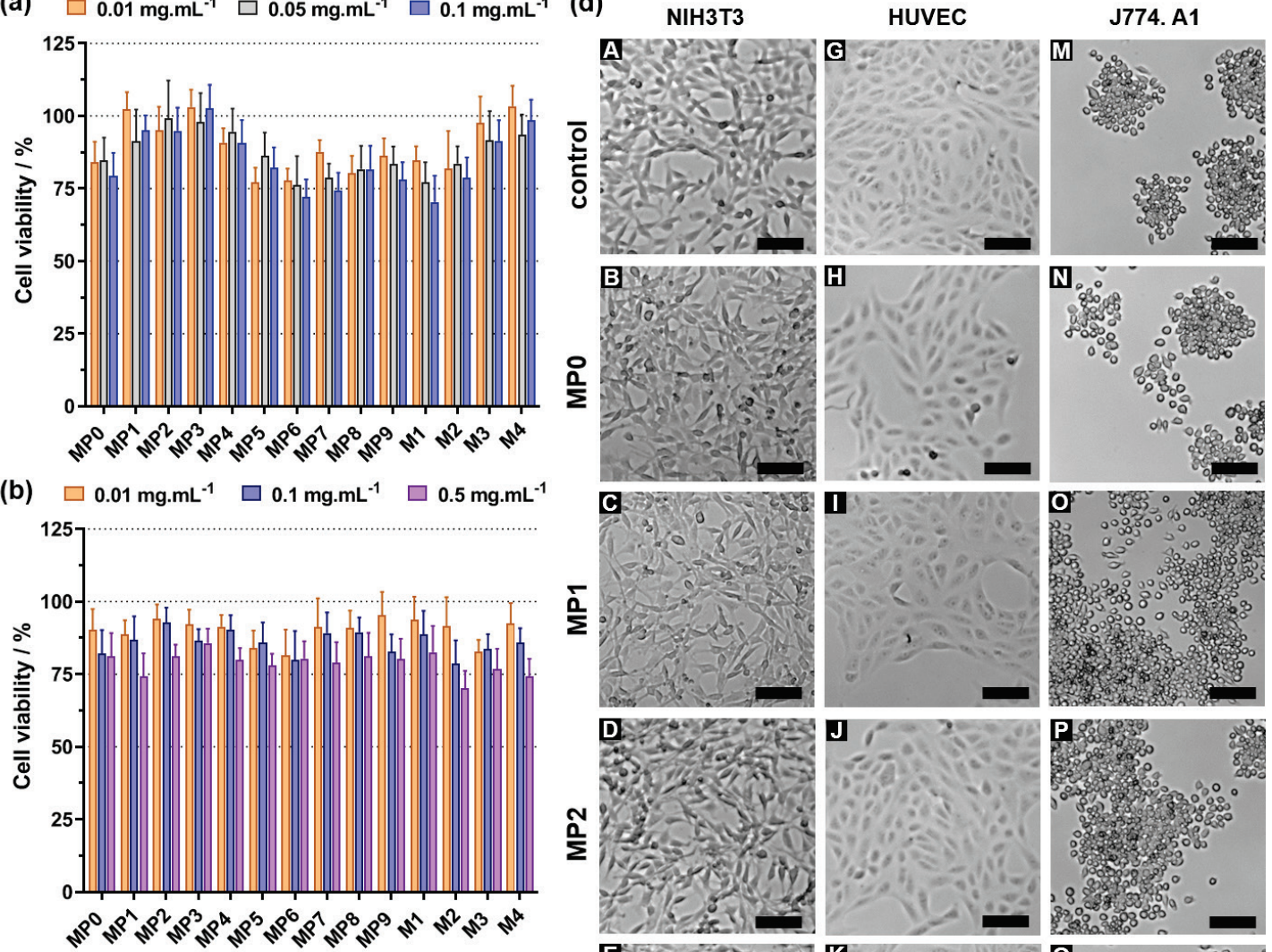

(c) $\square 0.01 \mathrm{mg} \cdot \mathrm{mL}^{-1} \quad \square 0.1 \mathrm{mg} \cdot \mathrm{mL}^{-1} \quad \square 0.5 \mathrm{mg} \cdot \mathrm{mL}^{-1}$
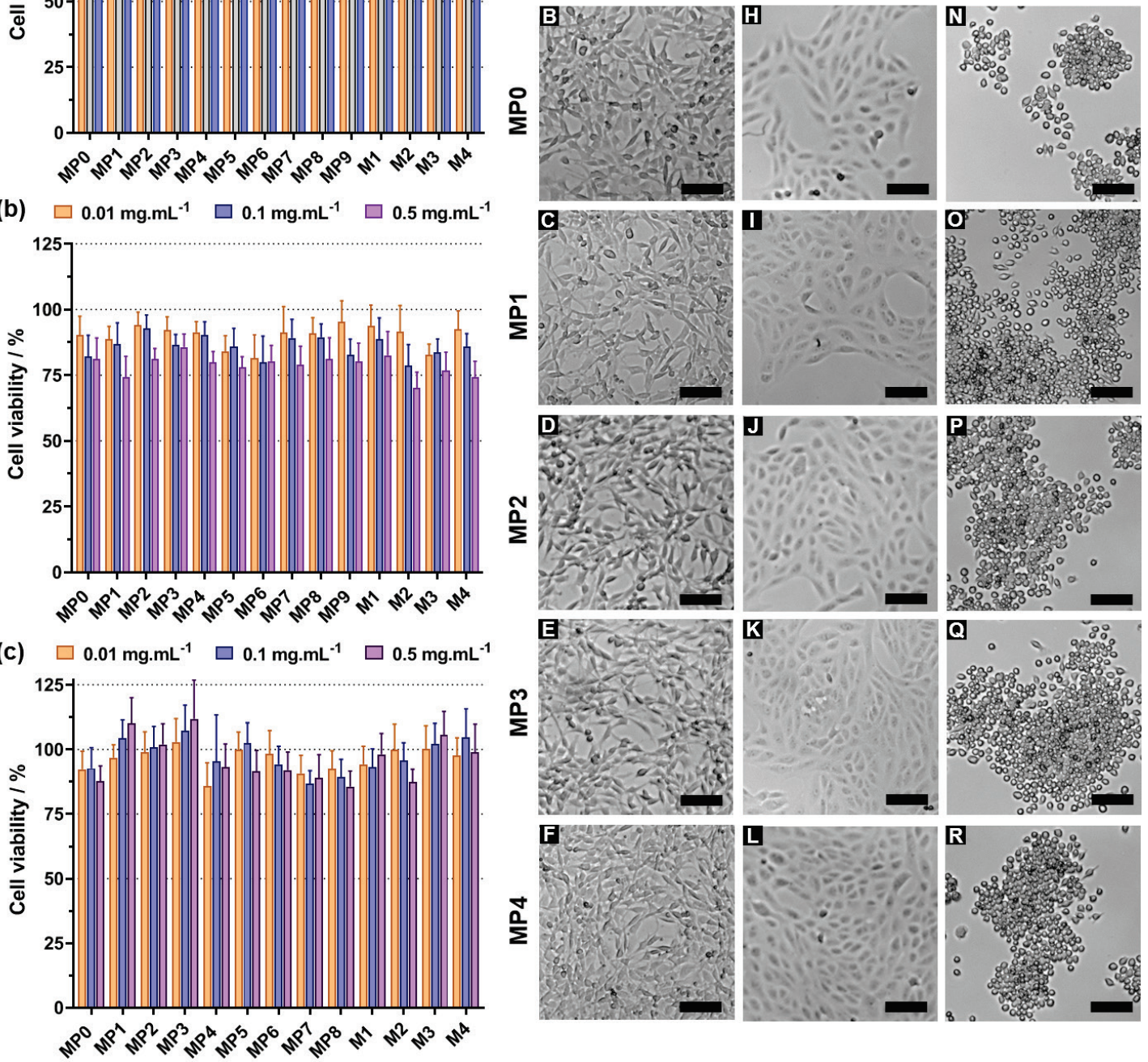

Figure 10. Cell viability (MTT assay) after incubation of: (a) NIH/3T3 cells; (b) HUVEC cells and (c) J774.A1 cells with $\mathbf{O E G}_{\mathbf{m}}-\mathbf{L}_{\mathbf{n}} \mathbf{M P}\left(f_{\mathrm{MPDL}, 0}=0-0.7\right.$, MP0-MP9) and $\mathbf{O E G}_{\mathbf{2 3}}-\mathbf{L}_{\mathbf{1 5 0}} \mathbf{M}$ $\left(f_{\mathrm{MDO}, 0}=0.2-0.7\right.$, M1-M4) nanoparticles at different concentrations. Results were expressed as percentage of absorption of treated cells $\pm \mathrm{SD}$ in comparison with untreated cells (control). (d) Representative optical images of NIH/3T3 (A-F), HUVEC (G-L), and J774.A1 cells (M-R) after incubation for $72 \mathrm{~h}$ with MP0-MP4 nanoparticles at $0.1 \mathrm{mg} \cdot \mathrm{mL}^{-1}$. Scale bar $=100 \mu \mathrm{m}$. 
Looking at each set of results individually, it appeared that increasing the nanoparticle concentration over this range had no significant influence on the viability of J774.A1 and NIH/3T3 cells, and only little influence on that of HUVEC cells (especially for OEG23-L150M nanoparticles), which seems to corroborate previous cytocompatibility studies on CKA-containing water-soluble copolymers. ${ }^{[52]}$ Increasing the amount of CKA however seemed to conduct to higher cell viabilities of NIH/3T3 cells especially for OEG23-L150MP and OEG23-L150M nanoparticles. No significant effect was observed on the three cell lines when increasing the POEGMA chain length with OEG52-L300MP nanoparticles.

An observation of cell morphology was performed after a 72-hour incubation period of the three cell lines with the nanoparticles at the same concentrations as a complementary method to the cell viability assays to assess their cytocompatibility (Figure 10d and Figure S16-23). Overall, cells treated with the nanoparticles, whatever their nature, exhibited no noticeable difference in terms of morphology (e.g., roundlike shape for J774.A1 cells, cobblestone-like morphology for HUVEC cells and fibroblast-like shape for $\mathrm{NIH} / 3 \mathrm{~T} 3$ cells), size, density or cell proliferation compared to untreated cells, thus confirming the results from the cell viability assays. Therefore, there was no adverse effect of nanoparticles at these concentrations, regardless of the nature of the CKA, its content and the POEGMA chain length. In conclusion, all these results attested for their cytocompatibility and are promising for their ultimate biocompatibility. 


\section{Conclusion}

In this study, we reported on a simple two-step rROPISA process that allowed to readily produce stable, aqueous suspensions of mostly narrowly dispersed, degradable vinyl copolymer nanoparticles. It relied on RAFT-mediated copolymerization of LMA and CKA in DMF at $15 \mathrm{wt. \%}$ solid contents from a solvophilic POEGMA macro-CTA. The resulting nanoparticles were then transferred to water by simple dialysis during which their colloidal properties were maintained.

Several key structural parameters were varied such as the nature of the CKA, its content in the copolymer and the POEGMA macro-CTA chain length. It was shown that this two-step rROPISA process was perfectly applicable to the three main CKAs use in rROP (i.e., MPDL, BMDO and MDO) and led to tunable CKA contents up to 21 mol.\%, thus demonstrating its versatility and robustness. Increasing the POEGMA chain length helped to improve the colloidal properties upon transfer to water especially for high CKA contents. While MDO-containing nanoparticles could be directly transferred to water, the two-step rROPISA process was further optimized for MPDLand BMDO-containing copolymers by adding an intermediate dialysis in acetone. It allowed both high concentrations of narrowly dispersed nanoparticles in water to be obtained in the $80-250 \mathrm{~nm}$ range and removal of unreacted monomer.

Degradation experiments showed that both free copolymers and corresponding nanoparticles were degradable under accelerated conditions depending on their CKA content. Cytotoxicity studies performed on several libraries of nanoparticles via cell viability assays and cell morphology observations, showed no cytotoxicity up to 0.1 or 
$0.5 \mathrm{mg} \cdot \mathrm{mL}^{-1}$ on three representative healthy cell lines. With their PEG-based shell, which is known to confer stealth properties, these results make it possible to envisage the use of these nanoparticles in the biomedical field.

Given its benefits, we believe such a polymerization process to be a promising tool to generate degradable vinyl polymer nanoparticles with great potential for drug delivery applications. Importantly, such approach could also be beneficial to other research fields as degradable particles could favorably replace traditional latexes to yield more environmentally friendly materials. In this context, this two-step rROPISA process could be an important step forward against plastic pollution which has become one of the most pressing environmental problems.

\section{Acknowledgement}

We thank the China Scholarship Council (CSC) for the PhD fellowship (2017-2021) of CZ. The authors thank Claire Boulogne and Cynthia Gillet (I2BC, Gif-sur-Yvette, France) for technical assistance in TEM, Ana-Andreea Arteni and Malika Ouldali (I2BC, UMR 9198 Institut de Biologie Intégrative de la Cellule, Gif-sur-Yvette, France) for technical assistance in Cyro-TEM and Valerie Nicolas (MIPSIT, ChâtenayMalabry, France) for the technical assistance in optical microscopy. The CNRS is also acknowledged for financial support. 


\section{Table of Content}

A simple two-step radical ring-opening copolymerization-induced self-assembly (rROPISA) process that allowed to readily produce stable, aqueous suspensions of mostly narrowly dispersed, degradable vinyl copolymer nanoparticles.

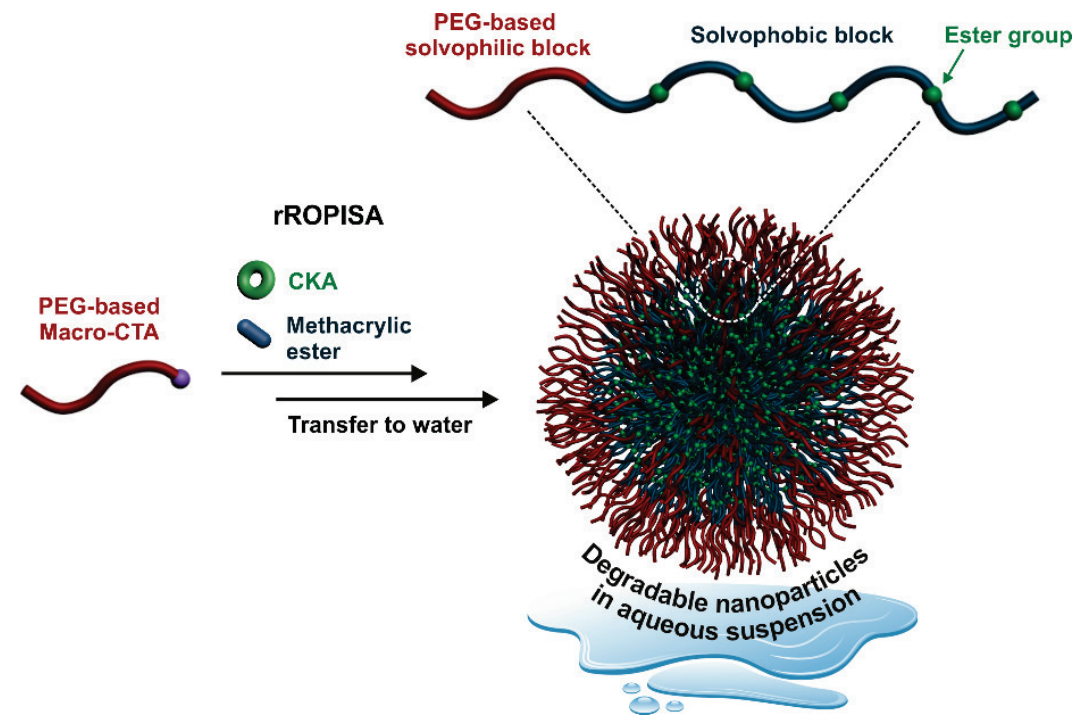

\section{Reference}

[1] T. Safra, F. Muggia, S. Jeffers, D. Tsao-Wei, S. Groshen, O. Lyass, R. Henderson, G. Berry, A. Gabizon, Annals of oncology: official journal of the European Society for Medical Oncology / ESMO 2000, 11, 1029-1033.

[2] P. Couvreur, C. Vauthier, Pharmaceutical Research 2006, 23, 1417-1450.

[3] K. S. Soppimath, T. M. Aminabhavi, A. R. Kulkarni, W. E. Rudzinski, Journal of Controlled Release 2001, 70, 1-20.

[4] W. B. Liechty, D. R. Kryscio, B. V Slaughter, N. A. Peppas, Annual review of chemical and biomolecular engineering 2010, 1, 149-173.

[5] V. Delplace, J. Nicolas, Nature Chemistry 2015, 7, 771-784.

[6] A. Tardy, J. Nicolas, D. Gigmes, C. Lefay, Y. Guillaneuf, Chemical Reviews 2017, 117, 1319-1406. 
[7] T. Pesenti, J. Nicolas, ACS Macro Letters 2020, 9, 1812-1835.

[8] J. M. Siebert, D. Baumann, A. Zeller, V. Mailänder, K. Landfester, Macromolecular Bioscience 2012, 12, 165-175.

[9] N. J. W. Penfold, J. Yeow, C. Boyer, S. P. Armes, ACS Macro Letters 2019, 8, 10291054.

[10] N. J. Warren, S. P. Armes, Journal of the American Chemical Society 2014, 136, 10174 10185.

[11] S. L. Canning, G. N. Smith, S. P. Armes, Macromolecules 2016, 49, 1985-2001.

[12] P. Gurnani, C. P. Bray, R. A. E. Richardson, R. Peltier, S. Perrier, Macromolecular Rapid Communications 2019, 40, 1800314.

[13] W.-J. Zhang, C.-Y. Hong, C.-Y. Pan, Macromolecules 2014, 47, 1664-1671.

[14] N. J. Warren, O. O. Mykhaylyk, A. J. Ryan, M. Williams, T. Doussineau, P. Dugourd, R. Antoine, G. Portale, S. P. Armes, Journal of the American Chemical Society 2015, 137, 1929-1937.

[15] C. Gonzato, M. Semsarilar, E. R. Jones, F. Li, G. J. P. Krooshof, P. Wyman, O. O. Mykhaylyk, R. Tuinier, S. P. Armes, Journal of the American Chemical Society 2014, 136, 11100-11106.

[16] N. J. W. Penfold, J. R. Whatley, S. P. Armes, Macromolecules 2019, 52, 1653-1662.

[17] D. B. Wright, M. A. Touve, L. Adamiak, N. C. Gianneschi, ACS Macro Letters 2017, 6, 925-929.

[18] V. Delplace, S. Harrisson, A. Tardy, D. Gigmes, Y. Guillaneuf, J. Nicolas, Macromolecular Rapid Communications 2014, 35, 484-491.

[19] G. Wang, M. Schmitt, Z. Wang, B. Lee, X. Pan, L. Fu, J. Yan, S. Li, G. Xie, M. R. Bockstaller, K. Matyjaszewski, Macromolecules 2016, 49, 8605-8615.

[20] Y. Sha, M. A. Rahman, T. Zhu, Y. Cha, C. W. McAlister, C. Tang, Chemical Science 2019, 10, 9782-9787.

[21] S. Varlas, J. C. Foster, P. G. Georgiou, R. Keogh, J. T. Husband, D. S. Williams, R. K. O'Reilly, Nanoscale 2019, 11, 12643-12654.

[22] X. Wang, S. Man, J. Zheng, Z. An, ACS Macro Letters 2018, 7, 1461-1467.

[23] J. Yeow, O. R. Sugita, C. Boyer, ACS Macro Letters 2016, 5, 558-564.

[24] D. Le, F. Wagner, M. Takamiya, I.-L. Hsiao, G. Gil Alvaradejo, U. Strähle, C. Weiss, G. Delaittre, Chemical Communications 2019, 55, 3741-3744.

[25] Y. Ding, Q. Zhao, L. Wang, L. Huang, Q. Liu, X. Lu, Y. Cai, ACS Macro Letters 2019, 8, 943-946.

[26] S. Dong, W. Zhao, F. P. Lucien, S. Perrier, P. B. Zetterlund, Polymer Chemistry 2015, 6, 2249-2254.

[27] C. A. Figg, A. Simula, K. A. Gebre, B. S. Tucker, D. M. Haddleton, B. S. Sumerlin, Chemical Science 2015, 6, 1230-1236. 
[28] J. Yeow, J. Xu, C. Boyer, ACS Macro Letters 2015, 4, 984-990.

[29] B. Karagoz, L. Esser, H. T. Duong, J. S. Basuki, C. Boyer, T. P. Davis, Polymer Chemistry 2014, 5, 350-355.

[30] W. Zhao, H. T. Ta, C. Zhang, A. K. Whittaker, Biomacromolecules 2017, 18, 11451156.

[31] W.-J. Zhang, C.-Y. Hong, C.-Y. Pan, Biomacromolecules 2016, 17, 2992-2999.

[32] W.-J. Zhang, C.-Y. Hong, C.-Y. Pan, Macromolecular Rapid Communications 2019, 40, 1800279.

[33] L. D. Blackman, S. Varlas, M. C. Arno, A. Fayter, M. I. Gibson, R. K. O’Reilly, ACS Macro Letters 2017, 6, 1263-1267.

[34] S. Kaga, N. P. Truong, L. Esser, D. Senyschyn, A. Sanyal, R. Sanyal, J. F. Quinn, T. P. Davis, L. M. Kaminskas, M. R. Whittaker, Biomacromolecules 2017, 18, 3963-3970.

[35] V. Ladmiral, M. Semsarilar, I. Canton, S. P. Armes, Journal of the American Chemical Society 2013, 135, 13574-13581.

[36] C. Grazon, P. Salas-Ambrosio, E. Ibarboure, A. Buol, E. Garanger, M. W. Grinstaff, S. Lecommandoux, C. Bonduelle, Angewandte Chemie International Edition 2020, 59, $622-626$.

[37] E. Guégain, C. Zhu, E. Giovanardi, J. Nicolas, Macromolecules 2019, 52, 3612-3624.

[38] C. Zhu, J. Nicolas, Polymer Chemistry 2021, 12, 594-607.

[39] F. M. Veronese, Biomaterials 2001, 22, 405-417.

[40] F. Veronese and J.M. Harris, Advanced Drug Delivery Reviews 2002, 54, 453-456.

[41] M. J. Roberts, M. D. Bentley, J. M. Harris, Advanced Drug Delivery Reviews 2002, 54, 459-476.

[42] R. Duncan, Nature Reviews Drug Discovery 2003, 2, 347-360.

[43] J. M. Harris, R. B. Chess, Nature Reviews Drug Discovery 2003, 2, 214-221.

[44] J. Tran, E. Guégain, N. Ibrahim, S. Harrisson, J. Nicolas, Polymer Chemistry 2016, 7, $4427-4435$.

[45] E. Guégain, J. Tran, Q. Deguettes, J. Nicolas, Chemical Science 2018, 9, 8291-8306.

[46] S. Stolnik, L. Illum, S. S. Davis, Advanced Drug Delivery Reviews 1995, 16, 195-214.

[47] R. Gref, Y. Minamitake, M. T. Peracchia, V. Trubetskoy, V. Torchilin, R. Langer, Science 1994, 263, 1600-1603.

[48] G. Storm, S. O. Belliot, T. Daemen, D. D. Lasic, Advanced Drug Delivery Reviews 1995, 17, 31-48.

[49] E. Malikmammadov, T. E. Tanir, A. Kiziltay, V. Hasirci, N. Hasirci, PCL and PCLBased Materials in Biomedical Applications, Taylor \& Francis, 2018.

[50] M. R. Hill, E. Guégain, J. Tran, C. A. Figg, A. C. Turner, J. Nicolas, B. S. Sumerlin, ACS Macro Letters 2017, 6, 1071-1077. 
[51] E. Dalgakiran, H. Tatlipinar, Physical Chemistry Chemical Physics 2018, 20, 1538915399.

[52] V. Delplace, A. Tardy, S. Harrisson, S. Mura, D. Gigmes, Y. Guillaneuf, J. Nicolas, Biomacromolecules 2013, 14, 3769-3779.

[53] J. Tran, T. Pesenti, J. Cressonnier, C. Lefay, D. Gigmes, Y. Guillaneuf, J. Nicolas, Biomacromolecules 2019, 20, 305-317. 